\title{
Nonlinearity Valuation Adjustment
}

\section{Nonlinear Valuation Under Collateralization, Credit Risk, and Funding Costs}

\author{
Damiano Brigo, Qing D. Liu, Andrea Pallavicini and David Sloth
}

\begin{abstract}
We develop a consistent, arbitrage-free framework for valuing derivative trades with collateral, counterparty credit risk, and funding costs. Credit, debit, liquidity, and funding valuation adjustments (CVA, DVA, LVA, and FVA) are simply introduced as modifications to the payout cash flows of the trade position. The framework is flexible enough to accommodate actual trading complexities such as asymmetric collateral and funding rates, replacement close-out, and re-hypothecation of posted collateral-all aspects which are often neglected. The generalized valuation equation takes the form of a forward-backward SDE or semi-linear PDE. Nevertheless, it may be recast as a set of iterative equations which can be efficiently solved by our proposed least-squares Monte Carlo algorithm. We implement numerically the case of an equity option and show how its valuation changes when including the above effects. In the paper we also discuss the financial impact of the proposed valuation framework and of nonlinearity more generally. This is fourfold: First, the valuation equation is only based on observable market rates, leaving the value of a derivatives transaction invariant to any theoretical risk-free rate. Secondly, the presence of funding costs makes the valuation problem a highly recursive and nonlinear one. Thus, credit and funding risks are non-separable in general, and despite common practice in banks, CVA, DVA, and FVA cannot be treated as purely additive adjustments without running the risk of double counting. To quantify the valuation error that can be attributed to double counting, we introduce a "nonlinearity valuation adjustment" (NVA) and show that its magnitude can be significant under asymmetric funding rates and replacement close-out at default. Thirdly, as trading
\end{abstract}

D. Brigo ( $\varangle)$ ? Q.D. Liu · A. Pallavicini

Department of Mathematics, Imperial College London, London, UK

e-mail: damiano.brigo@imperial.ac.uk

Q.D. Liu

e-mail: daphne.q.liu@gmail.com

A. Pallavicini

Banca IMI, largo Mattioli 3, Milan 20121, Italy

e-mail: andrea.pallavicini@imperial.ac.uk

D. Sloth

Rate Options \& Inflation Trading, Danske Bank, Copenhagen, Denmark

e-mail: dap@danskebank.com 
parties cannot observe each others' liquidity policies nor their respective funding costs, the bilateral nature of a derivative price breaks down. The value of a trade to a counterparty will not be just the opposite of the value seen by the bank. Finally, valuation becomes aggregation-dependent and portfolio values cannot simply be added up. This has operational consequences for banks, calling for a holistic, consistent approach across trading desks and asset classes.

Keywords Nonlinear valuation - Nonlinear valuation adjustment NVA $\cdot$ Credit risk Credit valuation adjustment CVA $\cdot$ Funding costs $\cdot$ Funding valuation adjustment FVA $\cdot$ Consistent valuation $\cdot$ Collateral

\section{Introduction}

Recent years have seen an unprecedented interest among banks in understanding the risks and associated costs of running a derivatives business. The financial crisis in 2007-2008 made banks painfully aware that derivative transactions involve a number of risks, e.g., credit or liquidity risks that they had previously overlooked or simply ignored. The industry practice for dealing with these issues comes in the form of a series of price adjustments to the classic, risk-neutral price definition of a contingent claim, often coined under mysteriously sounding acronyms such as CVA, DVA, or FVA. ${ }^{1}$ The credit valuation adjustment (CVA) corrects the price for the expected costs to the dealer due to the possibility that the counterparty may default, while the so-called debit valuation adjustment (DVA) is a correction for the expected benefits to the dealer due to his own default risk. Dealers also make adjustments due to the costs of funding the trade. This practice is known as a liquidity and funding valuation adjustment (LVA, FVA). Recent headlines such as J.P. Morgan taking a hit of $\$ 1.5$ billion in its 2013 fourth-quarter earnings due to funding valuation adjustments underscores the sheer importance of accounting for FVA.

In this paper we develop an arbitrage-free valuation approach of collateralized as well as uncollateralized trades that consistently accounts for credit risk, collateral, and funding costs. We derive a general valuation equation where CVA, DVA, collateral, and funding costs are introduced simply as modifications of payout cash flows. This approach can also be tailored to address trading through a central clearing house (CCP) with initial and variation margins as investigated in Brigo and Pallavicini [6]. In addition, our valuation approach does not put any restrictions on the banks' liquidity policies and hedging strategies, while accommodating asymmetric collateral and funding rates, collateral rehypothecation, and risk-free/replacement close-out conventions. We present an invariance theorem showing that our valuation equa-

\footnotetext{
${ }^{1}$ Recently, a new adjustment, the so-called KVA or capital valuation adjustment, has been proposed to account for the capital cost of a derivatives transaction (see e.g. Green et al. [26]). Following the financial crisis, banks are faced by more severe capital requirements and leverage constraints put forth by the Basel Committee and local authorities. Despite being a key issue for the industry, we will not consider costs of capital in this paper.
} 
tions do not depend on some unobservable risk-free rates; valuation is purely based on observable market rates. The invariance theorem has appeared first implicitly in Pallavicini et al. [33], and is studied in detail in Brigo et al. [15], a version of which is in this same volume.

Several studies have analyzed the various valuation adjustments separately, but few have tried to build a valuation approach that consistently takes collateralization, counterparty credit risk, and funding costs into account. Under unilateral default risk, i.e., when only one party is defaultable, Brigo and Masetti [4] consider valuation of derivatives with CVA, while particular applications of their approach are given in Brigo and Pallavicini [5], Brigo and Chourdakis [3], and Brigo et al. [8]; see Brigo et al. [11] for a summary. Bilateral default risk appears in Bielecki and Rutkowski [1], Brigo and Capponi [2], Brigo et al. [9] and Gregory [27] who price both the CVA and DVA of a derivatives deal. The impact of collateralization on default risk has been investigated in Cherubini [20] and more recently in Brigo et al. [7, 12]. Assuming no default risk, Piterbarg [36] provides an initial analysis of collateralization and funding risk in a stylized Black-Scholes economy. Morini and Prampolini [31], Fries [25] and Castagna [19] consider basic implications of funding in presence of default risk. However, the most comprehensive attempts to develop a consistent valuation framework are those of Burgard and Kjaer [16, 17], Crépey [21-23], Crépey et al. [24], Pallavicini et al. [33, 34], and Brigo et al. [13, 14].

We follow the works of Pallavicini et al. [34], Brigo et al. [13, 14], and Sloth [37] and consider a general valuation framework that fully and consistently accounts for collateralization, counterparty credit risk, and funding risk when pricing a derivatives trade. We find that the precise patterns of funding-adjusted values depend on a number of factors, including the asymmetry between borrowing and lending rates. Moreover, the introduction of funding risk creates a highly recursive and nonlinear valuation problem. The inherent nonlinearity manifests itself in the valuation equations by taking the form of semi-linear PDEs or BSDEs.

Thus, valuation under funding risk poses a computationally challenging problem; funding and credit costs do not split up in a purely additive way. A consequence of this is that valuation becomes aggregation-dependent. Portfolio values do not simply add up, making it difficult for banks to create CVA and FVA desks with separate and clearcut responsibilities. Nevertheless, banks often make such simplifying assumptions when accounting for the various price adjustments. This can be done, however, only at the expense of tolerating some degree of double counting in the different valuation adjustments.

We introduce the concept of nonlinearity valuation adjustment (NVA) to quantify the valuation error that one makes when treating CVA, DVA, and FVA as separate, additive terms. In particular, we examine the financial error of neglecting nonlinearities such as asymmetric borrowing and lending funding rates and by substituting replacement close-out at default by the more stylized risk-free close-out assumption. We analyze the large scale implications of nonlinearity of the valuation equations: non-separability of risks, aggregation dependence in valuation, and local valuation measures as opposed to universal ones. Finally, our numerical results confirm that 
NVA and asymmetric funding rates can have a non-trivial impact on the valuation of financial derivatives.

To summarize, the financial implications of our valuation framework are fourfold:

- Valuation is invariant to any theoretical risk-free rate and only based on observable market rates.

- Valuation is a nonlinear problem under asymmetric funding and replacement closeout at default, making funding and credit risks non-separable.

- Valuation is no longer bilateral because counterparties cannot observe each others' liquidity policies nor their respective funding costs.

- Valuation is aggregation-dependent and portfolio values can no longer simply be added up.

The above points stress the fact that we are dealing with values rather than prices. By this, we mean to distinguish between the unique price of an asset in a complete market with a traded risk-free bank account and the value a bank or market participant attributes to the particular asset. Nevertheless, in the following, we will use the terms price and value interchangeably to mean the latter. The paper is organized as follows. Section 2 describes the general valuation framework with collateralized credit, debit, liquidity, and funding valuation adjustments. Section 3 derives an iterative solution of the pricing equation as well as a continuous-time approximation. Section 4 introduces the nonlinearity valuation adjustment and provides numerical results for specific valuation examples. Finally, Sect. 5 concludes the paper.

\section{Trading Under Collateralization, Close-Out Netting, and Funding Risk}

In this section we develop a general risk-neutral valuation framework for OTC derivative deals. The section clarifies how the traditional pre-crisis derivative price is consistently adjusted to reflect the new market realities of collateralization, counterparty credit risk, and funding risk. We refer to the two parties of a credit-risky deal as the investor or dealer ("I") on one side and the counterparty or client ("C") on the other.

We now introduce the mathematical framework we will use. We point out that the focus here is not on mathematics but on building the valuation framework. Full mathematical subtleties are left for other papers and may motivate slightly different versions of the cash flows, see for example Brigo et al. [15]. More details on the origins of the cash flows used here are in Pallavicini et al. [33, 34].

Fixing the time horizon $T \in \mathbb{R}_{+}$of the deal, we define our risk-neutral valuation model on the probability space $\left(\Omega, \mathscr{G},\left(\mathscr{G}_{t}\right)_{t \in[0, T]}, \mathbb{Q}\right)$. $\mathbb{Q}$ is the risk-neutral probability measure ideally associated with the locally risk-free bank account numeraire growing at the risk-free rate $r$. The filtration $\left(\mathscr{G}_{t}\right)_{t \in[0, T]}$ models the flow of information of the whole market, including credit, such that the default times of the investor $\tau_{I}$ and the counterparty $\tau_{C}$ are $\mathscr{G}$-stopping times. We adopt the notational convention 
that $\mathbb{E}_{t}$ is the risk-neutral expectation conditional on the information $\mathscr{G}_{t}$. Moreover, we exclude the possibility of simultaneous defaults for simplicity and define the time of the first default event among the two parties as the stopping time

$$
\tau \triangleq\left(\tau_{I} \wedge \tau_{C}\right)
$$

In the sequel we adopt the view of the investor and consider the cash flows and consequences of the deal from her perspective. In other words, when we price the deal we obtain the value of the position to the investor. As we will see, with funding risk this price will not be the value of the deal to the counterparty with opposite sign, in general.

The gist of the valuation framework is conceptually simple and rests neatly on the classical finance disciplines of risk-neutral valuation and discounting cash flows. When a dealer enters into a derivatives deal with a client, a number of cash flows are exchanged, and just like valuation of any other financial claim, discounting these cash in- or outflows gives us a price of the deal. Post-crisis market practice includes four (or more) different types of cash flow streams occurring once a trading position has been entered: (i) Cash flows coming directly from the derivatives contract, such as payoffs, coupons, dividends, etc. We denote by $\pi(t, T)$ the sum of the discounted cash flows happening over the time period $(t, T]$ without including any credit, collateral, and funding effects. This is where classical derivatives valuation would usually stop and the price of a derivative contract with maturity $T$ would be given by

$$
V_{t}=\mathbb{E}_{t}[\pi(t, T)]
$$

This price assumes no credit risk of the parties involved and no funding risk of the trade. However, present-day market practice requires the price to be adjusted by taking further cash-flow transactions into account: (ii) Cash flows required by collateral margining. If the deal is collateralized, cash flows happen in order to maintain a collateral account that in the case of default will be used to cover any losses. $\gamma(t, T ; C)$ is the sum of the discounted margining costs over the period $(t, T]$ with $C$ denoting the collateral account. (iii) Cash flows exchanged once a default event has occurred. We let $\theta_{\tau}(C, \varepsilon)$ denote the on-default cash-flow with $\varepsilon$ being the residual value of the claim traded at default. Lastly, (iv) cash flows required for funding the deal. We denote the sum of the discounted funding costs over the period $(t, T]$ by $\varphi(t, T ; F)$ with $F$ being the cash account needed for funding the deal. Collecting the terms we obtain a consistent price $\bar{V}$ of a derivative deal taking into account counterparty credit risk, margining costs, and funding costs

$$
\begin{aligned}
\bar{V}_{t}(C, F)=\mathbb{E}_{t}[ & \pi(t, T \wedge \tau)+\gamma(t, T \wedge \tau ; C)+\varphi(t, T \wedge \tau ; F) \\
& \left.+\mathbf{1}_{\{t<\tau<T\}} D(t, \tau) \theta_{\tau}(C, \varepsilon)\right]
\end{aligned}
$$

where $D(t, \tau)=\exp \left(-\int_{t}^{\tau} r_{s} d s\right)$ is the risk-free discount factor. 
By using a risk-neutral valuation approach, we see that only the payout needs to be adjusted under counterparty credit and funding risk. In the following paragraphs we expand the terms of (1) and carefully discuss how to compute them.

\subsection{Collateralization}

The ISDA master agreement is the most commonly used framework for full and flexible documentation of OTC derivative transactions and is published by the International Swaps and Derivatives Association (ISDA [29]). Once agreed between two parties, the master agreement sets out standard terms that apply to all deals entered into between those parties. The ISDA master agreement lists two tools to mitigate counterparty credit risk: collateralization and close-out netting. Collateralization of a deal means that the party which is out-of-the-money is required to post collateralusually cash, government securities, or highly rated bonds-corresponding to the amount payable by that party in the case of a default event. The credit support annex (CSA) to the ISDA master agreement defines the rules under which the collateral is posted or transferred between counterparties. Close-out netting means that in the case of default, all transactions with the counterparty under the ISDA master agreement are consolidated into a single net obligation which then forms the basis for any recovery settlements.

Collateralization of a deal usually happens according to a margining procedure. Such a procedure involves that both parties post collateral amounts to or withdraw amounts from the collateral account $C$ according to their current exposure on prefixed dates $\left\{t_{1}, \ldots, t_{n}=T\right\}$ during the life of the deal, typically daily. Let $\alpha_{i}$ be the year fraction between $t_{i}$ and $t_{i+1}$. The terms of the margining procedure may, furthermore, include independent amounts, minimum transfer amounts, thresholds, etc., as described in Brigo et al. [7]. However, here we adopt a general description of the margining procedure that does not rely on the particular terms chosen by the parties.

We consider a collateral account $C$ held by the investor. Moreover, we assume that the investor is the collateral taker when $C_{t}>0$ and the collateral provider when $C_{t}<0$. The CSA ensures that the collateral taker remunerates the account $C$ at an accrual rate. If the investor is the collateral taker, he remunerates the collateral account by the accrual rate $c_{t}^{+}(T)$, while if he is the collateral provider, the counterparty remunerates the account at the rate $c_{t}^{-}(T) .{ }^{2}$ The effective accrual collateral rate $\tilde{c}_{t}(T)$ is defined as

$$
\tilde{c}_{t}(T) \triangleq c_{t}^{-}(T) \mathbf{1}_{\left\{C_{t}<0\right\}}+c_{t}^{+}(T) \mathbf{1}_{\left\{C_{t}>0\right\}} .
$$

\footnotetext{
${ }^{2}$ We stress the slight abuse of notation here: A plus and minus sign does not indicate that the rates are positive or negative parts of some other rate, but instead it tells which rate is used to accrue interest on the collateral according to the sign of the collateral account.
} 
More generally, to understand the cash flows originating from collateralization of the deal, let us consider the consequences of the margining procedure to the investor. At the first margin date, say $t_{1}$, the investor opens the account and posts collateral if he is out-of-the-money, i.e. if $C_{t_{1}}<0$, which means that the counterparty is the collateral taker. On each of the following margin dates $t_{k}$, the investor posts collateral according to his exposure as long as $C_{t_{k}}<0$. As collateral taker, the counterparty pays interest on the collateral at the accrual rate $c_{t_{k}}^{-}\left(t_{k+1}\right)$ between the following margin dates $t_{k}$ and $t_{k+1}$. We assume that interest accrued on the collateral is saved into the account and thereby directly included in the margining procedure and the close-out. Finally, if $C_{t_{n}}<0$ on the last margin date $t_{n}$, the investor closes the collateral account, given no default event has occurred in between. Similarly, for positive values of the collateral account, the investor is instead the collateral taker and the counterparty faces corresponding cash flows at each margin date. If we sum up all the discounted margining cash flows of the investor and the counterparty, we obtain

$$
\gamma(t, T \wedge \tau ; C) \triangleq \sum_{k=1}^{n-1} \mathbf{1}_{\left\{t \leqslant t_{k}<(T \wedge \tau)\right\}} D\left(t, t_{k}\right) C_{t_{k}}\left(1-\frac{P_{t_{k}}\left(t_{k+1}\right)}{P_{t_{k}}^{\tilde{c}}\left(t_{k+1}\right)}\right),
$$

with the zero-coupon bond $P_{t}^{\tilde{c}}(T) \triangleq\left[1+(T-t) \tilde{c}_{t}(T)\right]^{-1}$, and the risk-free zero coupon bond, related to the risk-free rate $r$, given by $P_{t}(T)$. If we adopt a first order expansion (for small $c$ and $r$ ), we can approximate

$$
\gamma(t, T \wedge \tau ; C) \approx \sum_{k=1}^{n-1} \mathbf{1}_{\left\{t \leqslant t_{k}<(T \wedge \tau)\right\}} D\left(t, t_{k}\right) C_{t_{k}} \alpha_{k}\left(r_{t_{k}}\left(t_{k+1}\right)-\tilde{c}_{t_{k}}\left(t_{k+1}\right)\right)
$$

where with a slight abuse of notation we call $\tilde{c}_{t}(T)$ and $r_{t}(T)$ the continuously (as opposed to simple) compounded interest rates associated with the bonds $P^{\tilde{c}}$ and $P$. This last expression clearly shows a cost of carry structure for collateral costs. If $C$ is positive to "I", then "I" is holding collateral and will have to pay (hence the minus sign) an interest $c^{+}$, while receiving the natural growth $r$ for cash, since we are in a risk-neutral world. In the opposite case, if "I" posts collateral, $C$ is negative to "I" and "I" receives interest $c^{-}$while paying the risk-free rate, as should happen when one shorts cash in a risk-neutral world.

A crucial role in collateral procedures is played by rehypothecation. We discuss rehypothecation and its inherent liquidity risk in the following.

\section{Rehypothecation}

Often the CSA grants the collateral taker relatively unrestricted use of the collateral for his liquidity and trading needs until it is returned to the collateral provider. Effectively, the practice of rehypothecation lowers the costs of remuneration of the provided collateral. However, while without rehypothecation the collateral provider can expect to get any excess collateral returned after honoring the amount payable on the deal, if rehypothecation is allowed the collateral provider runs the risk of losing a fraction or all of the excess collateral in case of default on the collateral taker's part. 
We denote the recovery fraction on the rehypothecated collateral by $R_{I}^{\prime}$ when the investor is the collateral taker and by $R_{C}^{\prime}$ when the counterparty is the collateral taker. The general recovery fraction on the market value of the deal that the investor receives in the case of default of the counterparty is denoted by $R_{C}$, while $R_{I}$ is the recovery fraction received by the counterparty if the investor defaults. The collateral provider typically has precedence over other creditors of the defaulting party in getting back any excess capital, which means $R_{I} \leqslant R_{I}^{\prime} \leqslant 1$ and $R_{C} \leqslant R_{C}^{\prime} \leqslant 1$. If no rehypothecation is allowed and the collateral is kept safe in a segregated account, we have that $R_{I}^{\prime}=R_{C}^{\prime}=1$.

\subsection{Close-Out Netting}

In case of default, all terminated transactions under the ISDA master agreement with a given counterparty are netted and consolidated into a single claim. This also includes any posted collateral to back the transactions. In this context the close-out amount plays a central role in calculating the on-default cash flows. The close-out amount is the costs or losses that the surviving party incurs when replacing the terminated deal with an economic equivalent. Clearly, the size of these costs will depend on which party survives so we define the close-out amount as

$$
\varepsilon_{\tau} \triangleq \mathbf{1}_{\left\{\tau=\tau_{C}<\tau_{I}\right\}} \varepsilon_{I, \tau}+\mathbf{1}_{\left\{\tau=\tau_{I}<\tau_{C}\right\}} \varepsilon_{C, \tau}
$$

where $\varepsilon_{I, \tau}$ is the close-out amount on the counterparty's default priced at time $\tau$ by the investor and $\varepsilon_{C, \tau}$ is the close-out amount if the investor defaults. Recall that we always consider the deal from the investor's viewpoint in terms of the sign of the cash flows involved. This means that if the close-out amount $\varepsilon_{I, \tau}$ as measured by the investor is positive, the investor is a creditor of the counterpaty, while if it is negative, the investor is a debtor of the counterparty. Analogously, if the close-out amount $\varepsilon_{C, \tau}$ to the counterparty but viewed from the investor is positive, the investor is a creditor of the counterparty, and if it is negative, the investor is a debtor to the counterparty.

We note that the ISDA documentation is, in fact, not very specific in terms of how to actually calculate the close-out amount. Since 2009, ISDA has allowed for the possibility to switch from a risk-free close-out rule to a replacement rule that includes the DVA of the surviving party in the recoverable amount. Parker and McGarry[35] and Weeber and Robson [40] show how a wide range of values of the close-out amount can be produced within the terms of ISDA. We refer to Brigo et al. [7] and the references therein for further discussions on these issues. Here, we adopt the approach of Brigo et al. [7] listing the cash flows of all the various scenarios that can occur if default happens. We will net the exposure against the pre-default value of the collateral $C_{\tau-}$ and treat any remaining collateral as an unsecured claim.

If we aggregate all these cash flows and the pre-default value of collateral account, we reach the following expression for the on-default cash-flow 


$$
\begin{aligned}
\theta_{\tau}(C, \varepsilon) \triangleq & \mathbf{1}_{\left\{\tau=\tau_{C}<\tau_{l}\right\}}\left(\varepsilon_{I, \tau}-\operatorname{LGD}_{C}\left(\varepsilon_{I, \tau}^{+}-C_{\tau^{-}}^{+}\right)^{+}-\operatorname{LGD}_{C}^{\prime}\left(\varepsilon_{I, \tau}^{-}-C_{\tau^{-}}^{-}\right)^{+}\right) \\
& +\mathbf{1}_{\left\{\tau=\tau_{I}<\tau_{C}\right\}}\left(\varepsilon_{C, \tau}-\operatorname{LGD}_{I}\left(\varepsilon_{C, \tau}^{-}-C_{\tau^{-}}^{-}\right)^{-}-\operatorname{LGD}_{I}^{\prime}\left(\varepsilon_{C, \tau}^{+}-C_{\tau^{-}}^{+}\right)^{-}\right) .
\end{aligned}
$$

We use the short-hand notation $\mathscr{X}^{+}:=\max (\mathscr{X}, 0)$ and $\mathscr{X}^{-}:=\min (\mathscr{X}, 0)$, and define the loss-given-default as $\mathrm{LGD}_{C} \triangleq 1-R_{C}$, and the collateral loss-givendefault as $\mathrm{LGD}_{C}^{\prime} \triangleq 1-R_{C}^{\prime}$. If both parties agree on the exposure, namely $\varepsilon_{I, \tau}=$ $\varepsilon_{C, \tau}=\varepsilon_{\tau}$, when we take the risk-neutral expectation in (1), we see that the price of the discounted on-default cash-flow,

$$
\begin{aligned}
\mathbb{E}_{t}\left[\mathbf{1}_{\{t<\tau<T\}} D(t, \tau) \theta_{\tau}(C, \varepsilon)\right]= & \mathbb{E}_{t}\left[\mathbf{1}_{\{t<\tau<T\}} D(t, \tau) \varepsilon_{\tau}\right] \\
& -\operatorname{CVA}(t, T ; C)+\operatorname{DVA}(t, T ; C),
\end{aligned}
$$

is the present value of the close-out amount reduced by the positive collateralized CVA and DVA terms

$$
\begin{aligned}
& \Pi_{\mathrm{CVAcoll}}(s)=\left(\operatorname{LGD}_{C}\left(\varepsilon_{I, s}^{+}-C_{s^{-}}^{+}\right)^{+}+\operatorname{LGD}_{C}^{\prime}\left(\varepsilon_{I, s}^{-}-C_{s-}^{-}\right)^{+}\right) \geq 0, \\
& \Pi_{\mathrm{DVAcoll}}(s)=-\left(\operatorname{LGD}_{I}\left(\varepsilon_{C, s}^{-}-C_{s-}^{-}\right)^{-}+\operatorname{LGD}_{I}^{\prime}\left(\varepsilon_{C, s}^{+}-C_{s-}^{+}\right)^{-}\right) \geq 0,
\end{aligned}
$$

and

$$
\begin{aligned}
& \operatorname{CVA}(t, T ; C) \triangleq \mathbb{E}_{t}\left[\mathbf{1}_{\left\{\tau=\tau_{C}<T\right\}} D(t, \tau) \Pi_{\mathrm{CVAcoll}}(\tau)\right], \\
& \operatorname{DVA}(t, T ; C) \triangleq \mathbb{E}_{t}\left[\mathbf{1}_{\left\{\tau=\tau_{I}<T\right\}} D(t, \tau) \Pi_{\mathrm{DVAcoll}}(\tau)\right] .
\end{aligned}
$$

Also, observe that if rehypothecation of the collateral is not allowed, the terms multiplied by $\mathrm{LGD}_{C}^{\prime}$ and $\mathrm{LGD}_{I}^{\prime}$ drop out of the CVA and DVA calculations.

\subsection{Funding Risk}

The hedging strategy that perfectly replicates the no-arbitrage price of a derivative is formed by a position in cash and a position in a portfolio of hedging instruments. When we talk about a derivative deal's funding, we essentially mean the cash position that is required as part of the hedging strategy, and with funding costs we refer to the costs of maintaining this cash position. If we denote the cash account by $F$ and the risky asset account by $H$, we get

$$
\bar{V}_{t}=F_{t}+H_{t} .
$$

In the classical Black-Scholes-Merton theory, the risky part $H$ of the hedge would be a delta position in the underlying stock, whereas the locally risk-free (cash) part $F$ would be a position in the risk-free bank account. If the deal is collateralized, the margining procedure is included in the deal definition insuring that funding of 
the collateral is automatically taken into account. Moreover, if rehypothecation is allowed for the collateralized deal, the collateral taker can use the posted collateral as a funding source and thereby reduce or maybe even eliminate the costs of funding the deal. Thus, we have the following two definitions of the funding account: If rehypothecation of the posted collateral is allowed,

$$
F_{t} \triangleq \bar{V}_{t}-C_{t}-H_{t}
$$

and if such rehypothecation is forbidden, we have

$$
F_{t} \triangleq \bar{V}_{t}-H_{t}
$$

By implication of (9) and (10) it is obvious that if the funding account $F_{t}>0$, the dealer needs to borrow cash to establish the hedging strategy at time $t$. Correspondingly, if the funding account $F_{t}<0$, the hedging strategy requires the dealer to invest surplus cash. Specifically, we assume the dealer enters a funding position on a discrete time-grid $\left\{t_{1}, \ldots, t_{m}\right\}$ during the life of the deal. Given two adjacent funding times $t_{j}$ and $t_{j+1}$, for $1 \leq j \leq m-1$, the dealer enters a position in cash equal to $F_{t_{j}}$ at time $t_{j}$. At time $t_{j+1}$ the dealer redeems the position again and either returns the cash to the funder if it was a long cash position and pays funding costs on the borrowed cash, or he gets the cash back if it was a short cash position and receives funding benefits as interest on the invested cash. We assume that these funding costs and benefits are determined at the start date of each funding period and charged at the end of the period.

Let $P_{t}^{\tilde{f}}(T)$ represent the price of a borrowing (or lending) contract measurable at $t$ where the dealer pays (or receives) one unit of cash at maturity $T>t$. We introduce the effective funding rate $\tilde{f}_{t}$ as a function: $\tilde{f}_{t}=f(t, F, H, C)$, assuming that it depends on the cash account $F_{t}$, hedging account $H_{t}$, and collateral account $C_{t}$. Moreover, the zero-coupon bond corresponding to the effective funding rate is defined as

$$
P_{t}^{\tilde{f}}(T) \triangleq\left[1+(T-t) \tilde{f}_{t}(T)\right]^{-1},
$$

If we assume that the dealer hedges the derivatives position by trading in the spot market of the underlying asset(s), and the hedging strategy is implemented on the same time-grid as the funding procedure of the deal, the sum of discounted cash flows from funding the hedging strategy during the life of the deal is equal to

$$
\begin{aligned}
\varphi(t, T \wedge & \tau ; F, H) \\
& =\sum_{j=1}^{m-1} \mathbf{1}_{\left\{t \leqslant t_{j}<(T \wedge \tau)\right\}} D\left(t, t_{j}\right)\left(F_{t_{j}}-\left(F_{t_{j}}+H_{t_{j}}\right) \frac{P_{t_{j}}\left(t_{j+1}\right)}{P_{t_{j}}^{\tilde{f}}\left(t_{j+1}\right)}+H_{t_{j}} \frac{P_{t_{j}}\left(t_{j+1}\right)}{P_{t_{j}}^{\tilde{f}}\left(t_{j+1}\right)}\right) \\
& =\sum_{j=1}^{m-1} \mathbf{1}_{\left\{t \leqslant t_{j}<(T \wedge \tau)\right\}} D\left(t, t_{j}\right) F_{t_{j}}\left(1-\frac{P_{t_{j}}\left(t_{j+1}\right)}{P_{t_{j}}^{\tilde{f}}\left(t_{j+1}\right)}\right) .
\end{aligned}
$$


This is, strictly speaking, a discounted payout and the funding cost or benefit at time $t$ is obtained by taking the risk-neutral expectation of the above cash flows. For a trading example giving more details on how the above formula for $\varphi$ originates, see Brigo et al. [15].

As we can see from Eq. (11), the dependence of hedging account dropped off from the funding procedure. For modeling convenience, we can define the effective funding rate $\tilde{f}_{t}$ faced by the dealer as

$$
\tilde{f}_{t}(T) \triangleq f_{t}^{-}(T) \mathbf{1}_{\left\{F_{t}<0\right\}}+f_{t}^{+}(T) \mathbf{1}_{\left\{F_{t}>0\right\}}
$$

A related framework would be to consider the hedging account $H$ as being perfectly collateralized and use the collateral to fund hedging, so that there is no funding cost associated with the hedging account.

As with collateral costs mentioned earlier, we may rewrite the cash flows for funding as a first order approximation in continuously compounded rates $\tilde{f}$ and $r$ associated to the relevant bonds. We obtain

$$
\varphi(t, T \wedge \tau ; F) \approx \sum_{j=1}^{m-1} \mathbf{1}_{\left\{t \leqslant t_{j}<(T \wedge \tau)\right\}} D\left(t, t_{j}\right) F_{t_{j}} \alpha_{j}\left(r_{t_{j}}\left(t_{j+1}\right)-\tilde{f}_{t_{j}}\left(t_{j+1}\right)\right),
$$

We should also mention that, occasionally, we may include the effects of repo markets or stock lending in our framework. In general, we may borrow/lend the cash needed to establish $H$ from/to our treasury, and we may then use the risky asset in $H$ for repo or stock lending/borrowing in the market. This means that we could include the funding costs and benefits coming from this use of the risky asset. Here, we assume that the bank's treasury automatically recognizes this benefit or cost at the same rate $\tilde{f}$ as used for cash, but for a more general analysis involving repo rate $\tilde{h}$ please refer to, for example, Pallavicini et al. [34], Brigo et al. [15].

The particular positions entered by the dealer to either borrow or invest cash according to the sign and size of the funding account depend on the bank's liquidity policy. In the following we discuss two possible cases: One where the dealer can fund at rates set by the bank's treasury department, and another where the dealer goes to the market directly and funds his trades at the prevailing market rates. As a result, the funding rates and therefore the funding effect on the price of a derivative deal depends intimately on the chosen liquidity policy.

\section{Treasury Funding}

If the dealer funds the hedge through the bank's treasury department, the treasury determines the funding rates $f^{ \pm}$faced by the dealer, often assuming average funding costs and benefits across all deals. This leads to two curves as functions of maturity; one for borrowing funds $f^{+}$and one for lending funds $f^{-}$. After entering a funding position $F_{t_{j}}$ at time $t_{j}$, the dealer faces the following discounted cash-flow

$$
\Phi_{j}\left(t_{j}, t_{j+1} ; F\right) \triangleq-N_{t_{j}} D\left(t_{j}, t_{j+1}\right)
$$


with

$$
N_{t_{j}} \triangleq \frac{F_{t_{j}}^{-}}{P_{t_{j}}^{f^{-}}\left(t_{j+1}\right)}+\frac{F_{t_{j}}^{+}}{P_{t_{j}}^{f^{+}}\left(t_{j+1}\right)}
$$

Under this liquidity policy, the treasury — and not the dealer himself — is in charge of debt valuation adjustments due to funding-related positions. Also, being entities of the same institution, both the dealer and the treasury disappear in case of default of the institution without any further cash flows being exchanged and we can neglect the effects of funding in this case. So, when default risk is considered, this leads to following definition of the funding cash flows

$$
\bar{\Phi}_{j}\left(t_{j}, t_{j+1} ; F\right) \triangleq \mathbf{1}_{\left\{\tau>t_{j}\right\}} \Phi_{j}\left(t_{j}, t_{j+1} ; F\right) .
$$

Thus, the risk-neutral price of the cash flows due to the funding positions entered at time $t_{j}$ is

$$
\mathbb{E}_{t_{j}}\left[\bar{\Phi}_{j}\left(t_{j}, t_{j+1} ; F\right)\right]=-\mathbf{1}_{\left\{\tau>t_{j}\right\}}\left(F_{t_{j}}^{-} \frac{P_{t_{j}}\left(t_{j+1}\right)}{P_{t_{j}}^{f^{-}}\left(t_{j+1}\right)}+F_{t_{j}}^{+} \frac{P_{t_{j}}\left(t_{j+1}\right)}{P_{t_{j}}^{f^{+}}\left(t_{j+1}\right)}\right) .
$$

If we consider a sequence of such funding operations at each time $t_{j}$ during the life of the deal, we can define the sum of cash flows coming from all the borrowing and lending positions opened by the dealer to hedge the trade up to the first-default event

$$
\begin{aligned}
\varphi(t, T \wedge \tau ; F) & \triangleq \sum_{j=1}^{m-1} \mathbf{1}_{\left\{t \leqslant t_{j}<(T \wedge \tau)\right\}} D\left(t, t_{j}\right)\left(F_{t_{j}}+\mathbb{E}_{t_{j}}\left[\bar{\Phi}_{j}\left(t_{j}, t_{j+1} ; F\right)\right]\right) \\
& =\sum_{j=1}^{m-1} \mathbf{1}_{\left\{t \leqslant t_{j}<(T \wedge \tau)\right\}} D\left(t, t_{j}\right)\left(F_{t_{j}}-F_{t_{j}}^{-} \frac{P_{t_{j}}\left(t_{j+1}\right)}{P_{t_{j}}^{f^{-}}\left(t_{j+1}\right)}-F_{t_{j}}^{+} \frac{P_{t_{j}}\left(t_{j+1}\right)}{P_{t_{j}}^{f^{+}}\left(t_{j+1}\right)}\right) .
\end{aligned}
$$

In terms of the effective funding rate, this expression collapses to (11).

\section{Market Funding}

If the dealer funds the hedging strategy in the market-and not through the bank's treasury - the funding rates are determined by prevailing market conditions and are often deal-specific. This means that the rate $f^{+}$the dealer can borrow funds at may be different from the rate $f^{-}$at which funds can be invested. Moreover, these rates may differ across deals depending on the deals' notional, maturity structures, dealer-client relationship, and so forth. Similar to the liquidity policy of treasury funding, we assume a deal's funding operations are closed down in the case of default. Furthermore, as the dealer now operates directly on the market, he needs to include a DVA due to his funding positions when he marks-to-market his trading books. For simplicity, we assume that the funder in the market is default-free so no funding CVA 
needs to be accounted for. The discounted cash-flow from the borrowing or lending position between two adjacent funding times $t_{j}$ and $t_{j+1}$ is given by

$$
\begin{aligned}
\bar{\Phi}_{j}\left(t_{j}, t_{j+1} ; F\right) \triangleq & \mathbf{1}_{\left\{\tau>t_{j}\right\}} \mathbf{1}_{\left\{\tau_{I}>t_{j+1}\right\}} \Phi_{j}\left(t_{j}, t_{j+1} ; F\right) \\
& -\mathbf{1}_{\left\{\tau>t_{j}\right\}} \mathbf{1}_{\left\{\tau_{I}<t_{j+1}\right\}}\left(\operatorname{LGD}_{I} \varepsilon_{F, \tau_{I}}^{-}-\varepsilon_{F, \tau_{I}}\right) D\left(t_{j}, \tau_{I}\right),
\end{aligned}
$$

where $\varepsilon_{F, t}$ is the close-out amount calculated by the funder on the dealer's default

$$
\varepsilon_{F, \tau_{I}} \triangleq-N_{t_{j}} P_{\tau_{I}}\left(t_{j+1}\right) .
$$

To price this funding cash-flow, we take the risk-neutral expectation

$$
\mathbb{E}_{t_{j}}\left[\bar{\Phi}_{j}\left(t_{j}, t_{j+1} ; F\right)\right]=-\mathbf{1}_{\left\{\tau>t_{j}\right\}}\left(F_{t_{j}}^{-} \frac{P_{t_{j}}\left(t_{j+1}\right)}{P_{t_{j}}^{f^{-}}\left(t_{j+1}\right)}+F_{t_{j}}^{+} \frac{P_{t_{j}}\left(t_{j+1}\right)}{\bar{P}_{t_{j}}^{f^{+}}\left(t_{j+1}\right)}\right) .
$$

Here, the zero-coupon funding bond $\bar{P}_{t}^{f^{+}}(T)$ for borrowing cash is adjusted for the dealer's credit risk

$$
\bar{P}_{t}^{f^{+}}(T) \triangleq \frac{P_{t}^{f^{+}}(T)}{\mathbb{E}_{t}^{T}\left[\operatorname{LGD}_{I} \mathbf{1}_{\left\{\tau_{I}>T\right\}}+R_{I}\right]},
$$

where the expectation on the right-hand side is taken under the $T$-forward measure. Naturally, since the seniority could be different, one might assume a different recovery rate on the funding position than on the derivatives deal itself (see Crépey [21]). Extensions to this case are straightforward.

Next, summing the discounted cash flows from the sequence of funding operations through the life of the deal, we get a new expression for $\varphi$ that is identical to (14) where the $P_{t}^{f^{+}}(T)$ in the denominator is replaced by $\bar{P}_{t}^{f^{+}}(T)$. To avoid cumbersome notation, we will not explicitly write $\bar{P}^{f^{+}}$in the sequel, but just keep in mind that when the dealer funds directly in the market then $P^{f^{+}}$needs to be adjusted for funding $D V A$. Thus, in terms of the effective funding rate, we obtain (11).

\section{Generalized Derivatives Valuation}

In the previous section we analyzed the discounted cash flows of a derivatives trade and we developed a framework for consistent valuation of such deals under collateralized counterparty credit and funding risk. The arbitrage-free valuation framework is captured in the following theorem.

Theorem 1 (Generalized Valuation Equation)

The consistent arbitrage-free price $\bar{V}_{t}(C, F)$ of a contingent claim under counterparty credit risk and funding costs takes the form 


$$
\begin{aligned}
\bar{V}_{t}(C, F)=\mathbb{E}_{t}[ & \pi(t, T \wedge \tau)+\gamma(t, T \wedge \tau ; C)+\varphi(t, T \wedge \tau ; F) \\
+ & \left.\mathbf{1}_{\{t<\tau<T\}} D(t, \tau) \theta_{\tau}(C, \varepsilon)\right]
\end{aligned}
$$

where

1. $\pi(t, T \wedge \tau)$ is the discounted cash flows from the contract's payoff structure up to the first-default event.

2. $\gamma(t, T \wedge \tau ; C)$ is the discounted cash flows from the collateral margining procedure up to the first-default event and is defined in (3).

3. $\varphi(t, T \wedge \tau ; F)$ is the discounted cash flows from funding the hedging strategy up to the first-default event and is defined in (11).

4. $\theta_{\tau}(C, \varepsilon)$ is the on-default cash-flow with close-out amount $\varepsilon$ and is defined in (6).

Note that in general a nonlinear funding rate may lead to arbitrages since the choice of the martingale measure depends on the funding/hedging strategy (see Remark 4.2). One has to be careful in order to guarantee that the relevant valuation equation admits solutions. Existence and uniqueness of solutions in the framework of this paper are discussed from a fully mathematical point of view in Brigo et al. [15], a version of which, from the same authors, appears in this volume.

In general, while the valuation equation is conceptually clear-we simply take the expectation of the sum of all discounted cash flows of the trade under the riskneutral measure-solving the equation poses a recursive, nonlinear problem. The future paths of the effective funding rate $\tilde{f}$ depend on the future signs of the funding account $F$, i.e. whether we need to borrow or lend cash on each future funding date. At the same time, through the relations (9) and (10), the future sign and size of the funding account $F$ depend on the adjusted price $\bar{V}$ of the deal which is the quantity we are trying to compute in the first place. One crucial implication of this nonlinear structure of the valuation problem is the fact that FVA is generally not just an additive adjustment term, as often assumed. More importantly, we see that the celebrated conjecture identifying the DVA of a deal with its funding benefit is not fully general. Only in the unrealistic setting where the dealer can fund an uncollateralized trade at equal borrowing and lending rates, i.e. $f^{+}=f^{-}$, do we achieve the additive structure often assumed by practitioners. If the trade is collateralized, we need to impose even further restrictions as to how the collateral is linked to the price of the trade $\bar{V}$. It should be noted here that funding DVA (as referred to in the previous section) is similar to the DVA2 in Hull and White [28] and the concept of "windfall funding benefit at own default" in Crépey [22, 23]. In practice, however, funds transfer pricing and similar operations conducted by banks' treasuries clearly weaken the link between FVA and this source of DVA. The DVA of the funding instruments does not regard the bank's funding positions, but the derivatives position, and in general it does not match the FVA mainly due to the presence of funding netting sets.

Remark 1 (The Law of One Price.)

On the theoretical side, the generalized valuation equation shakes the foundation of the celebrated Law of One Price prevailing in classical derivatives pricing. Clearly, if we assume no funding costs, the dealer and counterparty agree on the price of 
the deal as both parties can-at least theoretically-observe the credit risk of each other through CDS contracts traded in the market and the relevant market risks, thus agreeing on CVA and DVA. In contrast, introducing funding costs, they will not agree on the FVA for the deal due to asymmetric information. The parties cannot observe each others' liquidity policies nor their respective funding costs associated with a particular deal. As a result, the value of a deal position will not generally be the same to the counterparty as to the dealer just with opposite sign.

Finally, as we adopt a risk-neutral valuation framework, we implicitly assume the existence of a risk-free interest rate. Indeed, since the valuation adjustments are included as additional cash flows and not as ad-hoc spreads, all the cash flows in (15) are discounted by the risk-free discount factor $D(t, T)$. Nevertheless, the risk-free rate is merely an instrumental variable of the general valuation equation. We clearly distinguish market rates from the theoretical risk-free rate avoiding the dubious claim that the over-night rates are risk free. In fact, as we will show in continuous time, if the dealer funds the hedging strategy of the trade through cash accounts available to him-whether as rehypothecated collateral or funds from the treasury, repo market, etc.- the risk-free rate vanishes from the valuation equation.

\subsection{Discrete-Time Solution}

Our purpose here is to turn the generalized valuation equation(15) into a set of iterative equations that can be solved by least-squares Monte Carlo methods. These methods are already standard in CVA and DVA calculations (Brigo and Pallavicini [5]). To this end, we introduce the auxiliary function

$$
\begin{aligned}
\bar{\pi}\left(t_{j}, t_{j+1} ; C\right) \triangleq & \pi\left(t_{j}, t_{j+1} \wedge \tau\right)+\gamma\left(t_{j}, t_{j+1} \wedge \tau ; C\right) \\
& +\mathbf{1}_{\left\{t_{j}<\tau<t_{j+1}\right\}} D\left(t_{j}, \tau\right) \theta_{\tau}(C, \varepsilon)
\end{aligned}
$$

which defines the cash flows of the deal occurring between time $t_{j}$ and $t_{j+1}$ adjusted for collateral margining costs and default risks. We stress the fact that the closeout amount used for calculating the on-default cash flow still refers to a deal with maturity $T$. If we then solve valuation equation (15) at each funding date $t_{j}$ in the time-grid $\left\{t_{1}, \ldots, t_{n}=T\right\}$, we obtain the deal price $\bar{V}$ at time $t_{j}$ as a function of the deal price on the next consecutive funding date $t_{j+1}$

$$
\begin{aligned}
\bar{V}_{t_{j}}= & \mathbb{E}_{t_{j}}\left[\bar{V}_{t_{j+1}} D\left(t_{j}, t_{j+1}\right)+\bar{\pi}\left(t_{j}, t_{j+1} ; C\right)\right] \\
& +\mathbf{1}_{\left\{\tau>t_{j}\right\}}\left(F_{t_{j}}-F_{t_{j}}^{-} \frac{P_{t_{j}}\left(t_{j+1}\right)}{P_{t_{j}}^{f^{-}}\left(t_{j+1}\right)}-F_{t_{j}}^{+} \frac{P_{t_{j}}\left(t_{j+1}\right)}{P_{t_{j}}^{f^{+}}\left(t_{j+1}\right)}\right),
\end{aligned}
$$

where, by definition, $\bar{V}_{t_{n}} \triangleq 0$ on the final date $t_{n}$. Recall the definitions of the funding account in (9) if no rehypothecation of collateral is allowed and in (10) if rehypothe- 
cation is permitted, we can then solve the above for the positive and negative parts of the funding account. The outcome of this exercise is a discrete-time iterative solution of the recursive valuation equation, provided in the following theorem.

Theorem 2 (Discrete-time Solution of the Generalized Valuation Equation) We may solve the full recursive valuation equation in Theorem 1 as a set of backwarditerative equations on the time-grid $\left\{t_{1}, \ldots, t_{n}=T\right\}$ with $\bar{V}_{t_{n}} \triangleq 0$. For $\tau<t_{j}$, we have

$$
\bar{V}_{t_{j}}=0 \text {, }
$$

while for $\tau>t_{j}$, we have

(i) if rehypothecation is forbidden:

$$
\left(\bar{V}_{t_{j}}-H_{t_{j}}\right)^{ \pm}=P_{t_{j}}^{\tilde{f}}\left(t_{j+1}\right)\left(\mathbb{E}_{t_{j}}^{t_{j+1}}\left[\bar{V}_{t_{j+1}}+\frac{\bar{\pi}\left(t_{j}, t_{j+1} ; C\right)-H_{t_{j}}}{D\left(t_{j}, t_{j+1}\right)}\right]\right)^{ \pm}
$$

(ii) if rehypothecation is allowed:

$$
\begin{aligned}
& \left(\bar{V}_{t_{j}}-C_{t_{j}}-H_{t_{j}}\right)^{ \pm} \\
& \quad=P_{t_{j}}^{\tilde{f}}\left(t_{j+1}\right)\left(\mathbb{E}_{t_{j}}^{t_{j+1}}\left[\bar{V}_{t_{j+1}}+\frac{\bar{\pi}\left(t_{j}, t_{j+1} ; C\right)-C_{t_{j}}-H_{t_{j}}}{D\left(t_{j}, t_{j+1}\right)}\right]\right)^{ \pm},
\end{aligned}
$$

where the expectations are taken under the $\mathbb{Q}^{t_{j+1}}$-forward measure.

The \pm sign in the theorem is supposed to stress the fact that the sign of the funding account, which determines the effective funding rate, depends on the sign of the conditional expectation. Further intuition may be gained by going to continuous time, which is the case we will now turn to.

\subsection{Continuous-Time Solution}

Let us consider a continuous-time approximation of the general valuation equation. This implies that collateral margining, funding, and hedging strategies are executed in continuous time. Moreover, we assume that rehypothecation is allowed, but similar results hold if this is not the case. By taking the time limit, we have the following expressions for the discounted cash flow streams of the deal

$$
\begin{array}{r}
\pi(t, T \wedge \tau)=\int_{t}^{T \wedge \tau} \pi(s, s+d s) D(t, s), \\
\gamma(t, T \wedge \tau ; C)=\int_{t}^{T \wedge \tau}\left(r_{s}-\tilde{c}_{s}\right) C_{s} D(t, s) d s,
\end{array}
$$




$$
\varphi(t, T \wedge \tau ; F)=\int_{t}^{T \wedge \tau}\left(r_{s}-\tilde{f}_{s}\right) F_{s} D(t, s) d s,
$$

where as mentioned earlier $\pi(t, t+d t)$ is the pay-off coupon process of the derivative contract and $r_{t}$ is the risk-free rate. These equations can also be immediately derived by looking at the approximations given in Eqs. (4) and (13).

Then, putting all the above terms together with the on-default cash flow as in Theorem 1, the recursive valuation equation yields

$$
\begin{aligned}
\bar{V}_{t}= & \int_{t}^{T} \mathbb{E}_{t}\left[\left(\mathbf{1}_{\{s<\tau\}} \pi(s, s+d s)+\mathbf{1}_{\{\tau \in d s\}} \theta_{s}(C, \varepsilon)\right) D(t, s)\right] \\
& +\int_{t}^{T} \mathbb{E}_{t}\left[\mathbf{1}_{\{s<\tau\}}\left(r_{s}-\tilde{c}_{s}\right) C_{s} D(t, s)\right] d s \\
& +\int_{t}^{T} \mathbb{E}_{t}\left[\mathbf{1}_{\{s<\tau\}}\left(r_{s}-\tilde{f}_{s}\right) F_{s}\right] D(t, s) d s .
\end{aligned}
$$

By recalling Eq. (7), we can write the following

Proposition 1 The value $\bar{V}_{t}$ of the claim under credit gap risk, collateral, and funding costs can be written as

$$
\bar{V}_{t}=V_{t}-C V A_{t}+D V A_{t}+L V A_{t}+F V A_{t}
$$

where $V_{t}$ is the price of the deal when there is no credit risk, no collateral, and no funding costs; LVA is a liquidity valuation adjustment accounting for the costs/benefits of collateral margining; FVA is the funding cost/benefit of the deal hedging strategy, and CVA and DVA are the familiar credit and debit valuation adjustments after collateralization. These different adjustments can be obtained by rewriting (17). One gets

$$
V_{t}=\int_{t}^{T} \mathbb{E}_{t}\left\{D(t, s) 1_{\{\tau>s\}}\left[\pi(s, s+d s)+1_{\{\tau \in d s\}} \varepsilon_{s}\right]\right\}
$$

and the valuation adjustments

$$
\begin{aligned}
C V A_{t} & =-\int_{t}^{T} \mathbb{E}\left\{D(t, s) 1_{\{\tau>s\}}\left[-\mathbf{1}_{\left\{s=\tau_{C}<\tau_{I}\right\}} \Pi_{\text {CVAcoll }}(s)\right]\right\} d u \\
D V A_{t} & =\int_{t}^{T} \mathbb{E}\left\{D(t, s) 1_{\{\tau>s\}}\left[\mathbf{1}_{\left\{s=\tau_{I}<\tau_{C}\right\}} \Pi_{D V A c o l l}(s)\right]\right\} d u \\
L V A_{t} & =\int_{t}^{T} \mathbb{E}_{t}\left\{D(t, s) 1_{\{\tau>s\}}\left(r_{s}-\tilde{c}_{s}\right) C_{s}\right\} d s \\
F V A_{t} & =\int_{t}^{T} \mathbb{E}\left\{D(t, s) 1_{\{\tau>s\}}\left[\left(r_{s}-\tilde{f}_{s}\right) F_{s}\right]\right\} d s
\end{aligned}
$$


As usual, CVA and DVA are both positive, while LVA and FVA can be either positive or negative. Notice that if $\tilde{c}$ equals the risk-free rate, LVA vanishes. Similarly, FVA vanishes if the funding rate $\tilde{f}$ is equal to the risk-free rate.

We note that there is no general consensus on our definition of LVA and other authors may define it differently. For instance, Crépey [21-23] refers to LVA as the liquidity component (i.e., net of credit) of the funding valuation adjustment.

We now take a number of heuristic steps. A more formal analysis in terms of FBSDEs or PDEs is, for example, provided in Brigo et al. [15]. For simplicity, we first switch to the default-free market filtration $\left(\mathscr{F}_{t}\right)_{t \geq 0}$. This step implicitly assumes a separable structure of our complete filtration $\left(\mathscr{G}_{t}\right)_{t \geq 0}$. We are also assuming that the basic portfolio cash flows $\pi(0, t)$ are $\mathscr{F}_{t}$-measurable and that default times of all parties are conditionally independent, given filtration $\mathscr{F}$.

Assuming the relevant technical conditions are satisfied, the Feynman-Kac theorem now allows us to write down the corresponding pre-default partial differential equation (PDE) of the valuation problem (further details may be found in Brigo et al. [13, 14], and Sloth [37]). This PDE could be solved directly as in Crépey [22]. However, if we apply the Feynman-Kac theorem again-this time going from the pre-default PDE to the valuation expectation - and integrate by parts, we arrive at the following result

Theorem 3 (Continuous-time Solution of the Generalized Valuation Equation) If we assume collateral rehypothecation and delta-hedging, we can solve the iterative equations of Theorem 2 in continuous time. We obtain

$$
\bar{V}_{t}=\int_{t}^{T} \mathbb{E}^{\tilde{f}}\left\{D(t, u ; \tilde{f}+\lambda)\left[\pi_{u}+\lambda_{u} \theta_{u}+\left(\tilde{f}_{u}-\tilde{c}_{u}\right) C_{u}\right] \mid \mathscr{F}_{t}\right\} d u
$$

where $\lambda_{t}$ is the first-to-default intensity, $\pi_{t} d t$ is shorthand for $\pi(t, t+d t)$, and the discount factor is defined as $D(t, s ; \xi) \triangleq e^{-\int_{t}^{s} \xi_{u} d u}$. The expectations are taken under the pricing measure $\mathbb{Q}^{\tilde{f}}$ for which the underlying risk factors grow at the rate $\tilde{f}$ when the underlying pays no dividend.

Theorem 3 decomposes the deal price $\bar{V}$ into three intuitive terms. The first term is the value of the deal cash flows, discounted at the funding rate plus credit. The second term is the price of the on-default cash-flow in excess of the collateral, which includes the CVA and DVA of the deal after collateralization. The last term collects the cost of collateralization. At this point it is very important to appreciate once again that $\tilde{f}$ depends on $F$, and hence on $V$.

Remark 2 (Deal-dependent Valuation Measure, Local Risk-neutral Measures).

Since the pricing measure depends on $\tilde{f}$ which in turn depends on the very value $\bar{V}$ we are trying to compute, we have that the valuation measure becomes deal/portfoliodependent. Claims sharing a common set of hedging instruments can be priced under a common measure. 
Finally, we stress once again a very important invariance result that first appeared in Pallavicini et al. [34] and studied in detail in a more mathematical setting in Brigo et al. [15]. The proof is immediate by inspection.

Theorem 4 (Invariance of the Valuation Equation wrt. the Short Rate $r_{t}$ ). Equation (20) for valuation under credit, collateral, and funding costs is completely governed by market rates; there is no dependence on a risk-free rate $r_{t}$. Whichever initial process is postulated for $r$, the final price is invariant to it.

\section{Nonlinear Valuation: A Numerical Analysis}

This section provides a numerical case study of the valuation framework outlined in the previous sections. We investigate the impact of funding risk on the price of a derivatives trade under default risk and collateralization. Also, we analyze the valuation error of ignoring nonlinearties of the general valuation problem. Specifically, to quantify this error, we introduce the concept of a nonlinearity valuation adjustment (NVA). A generalized least-squares Monte Carlo algorithm is proposed inspired by the simulation methods of Carriere [18], Longstaff and Schwartz [30], Tilley [38], and Tsitsiklis and Van Roy [39] for pricing American-style options. As the purpose is to understand the fundamental implications of funding risk and other nonlinearities, we focus on trading positions in relatively simple derivatives. However, the Monte Carlo method we propose below can be applied to more complex derivative contracts, including derivatives with bilateral payments.

\subsection{Monte Carlo Pricing}

Recall the recursive structure of the general valuation: The deal price depends on the funding decisions, while the funding strategy depends on the future price itself. The intimate relationship among the key quantities makes the valuation problem computationally challenging.

We consider $K$ default scenarios during the life of the deal-either obtained by simulation, bootstrapped from empirical data, or assumed in advance. For each firstto-default time $\tau$ corresponding to a default scenario, we compute the price of the deal $\bar{V}$ under collateralization, close-out netting, and funding costs. The first step of our simulation method entails simulating a large number of sample paths $N$ of the underlying risk factors $X$. We simulate these paths on the time-grid $\left\{t_{1}, \ldots, t_{m}=\right.$ $\left.T^{*}\right\}$ with step size $\Delta t=t_{j+1}-t_{j}$ from the assumed dynamics of the risk factors. $T^{*}$ is equal to the final maturity $T$ of the deal or the consecutive time-grid point following the first-default time $\tau$, whichever occurs first. For simplicity, we assume the time periods for funding decisions and collateral margin payments coincide with the simulation time grid. 
Given the set of simulated paths, we solve the funding strategy recursively in a dynamic programming fashion. Starting one period before $T^{*}$, we compute for each simulated path the funding decision $F$ and the deal price $\bar{V}$ according to the set of backward-inductive equations of Theorem 2. Note that while the reduced formulation of Theorem 3 may look simpler at first sight, avoiding the implicit recursive structure of Theorem 2, it would instead give us a forward-backward SDE problem to solve since the underlying asset now accrues at the funding rate which itself depends on $\bar{V}$. The algorithm then proceeds recursively until time zero. Ultimately, the total price of the deal is computed as the probability-weighted average of the individual prices obtained in each of the $K$ default scenarios.

The conditional expectations in the backward-inductive funding equations are approximated by across-path regressions based on least squares estimation similar to Longstaff and Schwartz [30]. We regress the present value of the deal price at time $t_{j+1}$, the adjusted payout cash flow between $t_{j}$ and $t_{j+1}$, the collateral account and funding account at time $t_{j}$ on basis functions $\psi$ of realizations of the underlying risk factors at time $t_{j}$ across the simulated paths. To keep notation simple, let us assume that we are exposed to only one underlying risk factor, e.g. a stock price. Specifically, the conditional expectations in the iterative equations of Theorem 2, taken under the risk-neutral measure, are equal to

$$
\mathbb{E}_{t_{j}}\left[\Xi_{t_{j}}\left(\bar{V}_{t_{j+1}}\right)\right]=\theta_{t_{j}}^{\prime} \psi\left(X_{t_{j}}\right),
$$

where we have defined $\Xi_{t_{j}}\left(\bar{V}_{t_{j+1}}\right) \triangleq D\left(t_{j}, t_{j+1}\right) \bar{V}_{t_{j+1}}+\bar{\pi}\left(t_{j}, t_{j+1} ; C\right)-C_{t_{j}}-H_{t_{j}}$. Note the $C_{t_{j}}$ term drops out if rehypothecation is not allowed. The usual least-squares estimator of $\theta$ is then given by

$$
\hat{\theta}_{t_{j}} \triangleq\left[\psi\left(X_{t_{j}}\right) \psi\left(X_{t_{j}}\right)^{\prime}\right]^{-1} \psi\left(X_{t_{j}}\right) \Xi_{t_{j}}\left(\bar{V}_{t_{j+1}}\right) .
$$

Orthogonal polynomials such as Chebyshev, Hermite, Laguerre, and Legendre may all be used as basis functions for evaluating the conditional expectations. We find, however, that simple power series are quite effective and that the order of the polynomials can be kept relatively small. In fact, linear or quadratic polynomials, i.e. $\psi\left(X_{t_{j}}\right)=\left(\mathbf{1}, X_{t_{j}}, X_{t_{j}}^{2}\right)^{\prime}$, are often enough.

Further complexities are added, as the dealer may_realistically_decide to hedge the full deal price $\bar{V}$. Now, the hedge $H$ itself depends on the funding strategy through $\bar{V}$, while the funding decision depends on the hedging strategy. This added recursion requires that we solve the funding and hedging strategies simultaneously. For example, if the dealer applies a delta-hedging strategy we can write, heuristically,

$$
H_{t_{j}}=\left.\frac{\partial \bar{V}}{\partial X}\right|_{t_{j}} X_{t_{j}} \approx \frac{\bar{V}_{t_{j+1}}-\left(1+\Delta t_{j} \tilde{f}_{t_{j}}\right) \bar{V}_{t_{j}}}{X_{t_{j+1}}-\left(1+\Delta t_{j} \tilde{f}_{t_{j}}\right) X_{t_{j}}} X_{t_{j}},
$$

and we obtain, in the case of rehypothecation, the following system of nonlinear equations 


$$
\left\{\begin{array}{l}
F_{t_{j}}-\frac{P_{t_{j}}^{\tilde{f}}\left(t_{j+1}\right)}{P_{t_{j}}\left(t_{j+1}\right)} \mathbb{E}_{t_{j}}\left[\Xi_{t_{j}}\left(\bar{V}_{t_{j+1}}\right)\right]=0, \\
H_{t_{j}}-\frac{\bar{V}_{t_{j+1}}-\left(1+\Delta t_{j} \tilde{f}_{t_{j}}\right) \bar{V}_{t_{j}}}{X_{t_{j+1}}-\left(1+\Delta t_{j} \tilde{f}_{t_{j}}\right) X_{t_{j}}} X_{t_{j}}=0, \\
\bar{V}_{t_{j}}=F_{t_{j}}+C_{t_{j}}+H_{t_{j}},
\end{array}\right.
$$

where all matrix operations are on an element-by-element basis. An analogous result holds when rehypothecation of the posted collateral is forbidden.

Each period and for each simulated path, we find the funding and hedging decisions by solving this system of equations, given the funding and hedging strategies for all future periods until the end of the deal. We apply a simple Newton-Raphson method to solve the system of nonlinear equations numerically, but instead of using the exact Jacobian, we approximate it by finite differences. As initial guess, we use the Black-Scholes delta position

$$
H_{t_{j}}^{0}=\Delta_{t_{j}}^{B S} X_{t_{j}}
$$

The convergence is quite fast and only a small number of iterations are needed in practice. Finally, if the dealer decides to hedge only the risk-free price of the deal, i.e. the classic derivative price $V$, the valuation problem collapses to a much simpler one. The hedge $H$ no longer depends on the funding decision and can be computed separately, and the numerical solution of the nonlinear equation system can be avoided altogether.

In the following we apply our valuation framework to the case of a stock or equity index option. Nevertheless, the methodology extends fully to any other derivatives transaction. For instance, applications to interest rate swaps can be found in Pallavicini and Brigo [32] and Brigo and Pallavicini [6].

\subsection{Case Outline}

Let $S_{t}$ denote the price of some stock or equity index and assume it evolves according to a geometric Brownian motion $d S_{t}=r S_{t} d t+\sigma S_{t} d W_{t}$ where $W$ is a standard Brownian motion under the risk-neutral measure. The risk-free interest rate $r$ is 100 bps, the volatility $\sigma$ is $25 \%$, and the current price of the underlying is $S_{0}=100$. The European call option is in-the-money and has strike $K=80$. The maturity $T$ of the deal is 3 years and, in the full case, we assume that the investor delta-hedges the deal according to (23). The usual default-free funding-free and collateral-free Black-Scholes price $V_{0}$ of the call option deal is given by

$$
V_{t}=S_{t} \Phi\left(d_{1}(t)\right)-K e^{-r(T-t)} \Phi\left(d_{2}(t)\right), \quad d_{1,2}=\frac{\ln \left(S_{t} / K\right)+\left(r \pm \sigma^{2} / 2\right)(T-t)}{\sigma \sqrt{T-t}},
$$


and for $t=0$ we get

$$
V_{0}=28.9
$$

with our choice of inputs. As usual, $\Phi$ is the cumulative distribution function of the standard normal random variable. In the usual setting, the hedge would not be (23) but a classical delta-hedging strategy based on $\Phi\left(d_{1}(t)\right)$.

We consider two simple discrete probability distributions of default. Both parties of the deal are considered default risky but can only default at year 1 or at year 2 . The localized joint default probabilities are provided in the matrices below. The rows denote the default time of the investor, while the columns denote the default times of the counterparty. For example, in matrix $D_{\text {low }}$ the event $\left(\tau_{I}=2 y r, \tau_{C}=1 y r\right)$ has a $3 \%$ probability and the first-to-default time is 1 year. Simultaneous defaults are introduced as an extension of our previous assumptions, and we determine the closeout amount by a random draw from a uniform distribution. If the random number is above 0.5 , we compute the close-out as if the counterparty defaulted first, and vice versa.

For the first default distribution, we have a low dependence between the default risk of the counterparty and the default risk of the investor

$$
\begin{gathered}
1 y r \\
D_{\text {low }}= \\
1 y r \\
2 y r \\
n . d .
\end{gathered}\left(\begin{array}{lll}
0.01 & 0.01 & 0.03 \\
0.03 & 0.01 & 0.05 \\
0.07 & 0.09 & 0.70
\end{array}\right), \quad \tau_{K}\left(D_{\text {low }}\right)=0.21
$$

where $n . d$. means no default and $\tau_{K}$ denotes the rank correlation as measured by Kendall's tau. In the second case, we have a high dependence between the two parties' default risk

$$
\begin{aligned}
& 1 y r \quad 2 y r \quad \text { n.d. } \\
& D_{\text {high }}=\begin{array}{l}
1 y r \\
2 y r \\
n . d .
\end{array}\left(\begin{array}{lll}
0.09 & 0.01 & 0.01 \\
0.03 & 0.11 & 0.01 \\
0.01 & 0.03 & 0.70
\end{array}\right), \quad \tau_{K}\left(D_{\text {high }}\right)=0.83
\end{aligned}
$$

Note also that the distributions are skewed in the sense that the counterparty has a higher default probability than the investor. The loss, given default, is $50 \%$ for both the investor and the counterparty and the loss on any posted collateral is considered the same. The collateral rates are chosen to be equal to the risk-free rate. We assume that the collateral account is equal to the risk-free price of the deal at each margin date, i.e. $C_{t}=V_{t}$. This is reasonable as the dealer and client will be able to agree on this price, in contrast to $\bar{V}_{t}$ due to asymmetric information. Also, choosing the collateral this way has the added advantage that the collateral account $C$ works as a control variate, reducing the variance of the least-squares Monte Carlo estimator of the deal price. 


\subsection{Preliminary Valuation Under Symmetric Funding and Without Credit Risk}

To provide some ball-park figures on the effect of funding risk, we first look at the case without default risk and without collateralization of the deal. We compare our Monte Carlo approach to the following two alternative (simplified) approaches:

(a) The Black-Scholes price where both discounting and the growth of the underlying happens at the symmetric funding rate

$$
\begin{aligned}
V_{t}^{(a)} & =\left(S_{t} \Phi\left(g_{1}(t)\right)-K e^{-\hat{f}(T-t)} \Phi\left(g_{2}(t)\right)\right), \\
g_{1,2} & =\frac{\ln \left(S_{t} / K\right)+\left(\hat{f} \pm \sigma^{2} / 2\right)(T-t)}{\sigma \sqrt{T-t}} .
\end{aligned}
$$

(b) We use the above FVA formula in Proposition 1 with some approximations. Since in a standard Black-Scholes setting $F_{t}=-K e^{-r(T-t)} \Phi\left(d_{2}(t)\right)$, we compute

$$
\begin{aligned}
\mathrm{FVA}^{(b)} & =(r-\hat{f}) \int_{0}^{T} \mathbb{E}_{0}\left\{e^{-r s}\left[F_{s}\right]\right\} d s \\
& =(\hat{f}-r) K e^{-r T} \int_{0}^{T} \mathbb{E}_{0}\left\{\Phi\left(d_{2}(s)\right)\right\} d s
\end{aligned}
$$

We illustrate the two approaches for a long position in an equity call option. Moreover, let the funding valuation adjustment in each case be defined by $\mathrm{FVA}^{(a, b)}=$ $V^{(a, b)}-V$. Figure 1 plots the resulting funding valuation adjustment with credit and collateral switched off under both simplified approaches and under the full valuation approach. Recall that if the funding rate is equal to the risk-free rate, the value of the call option collapses to the Black-Scholes price and the funding valuation adjustment is zero.

\section{Remark 3 (Current Market Practice for FVA).}

Looking at Fig. 1, it is important to realize that at the time of writing this paper, most market players would adopt a methodology like (a) or (b) for a simple call option. Even if borrowing or lending rates were different, most market players would average them and apply a common rate to borrowing and lending, in order to avoid nonlinearities. We notice that method (b) produces the same results as the quicker method (a) which simply replaces the risk-free rate by the funding rate. In the simple case without credit and collateral, and with symmetric borrowing and lending rates, we can show that this method is sound since it stems directly from (20). We also see that both methods (a) and (b) are quite close to the full numerical method we adopt. Overall both simplified methods (a) and (b) work well here, and there would be no need to implement the full machinery under these simplifying assumptions. However, once collateral, credit, and funding risks are in the picture, we have to abandon approximations like (a) or (b) and implement the full methodology instead. 


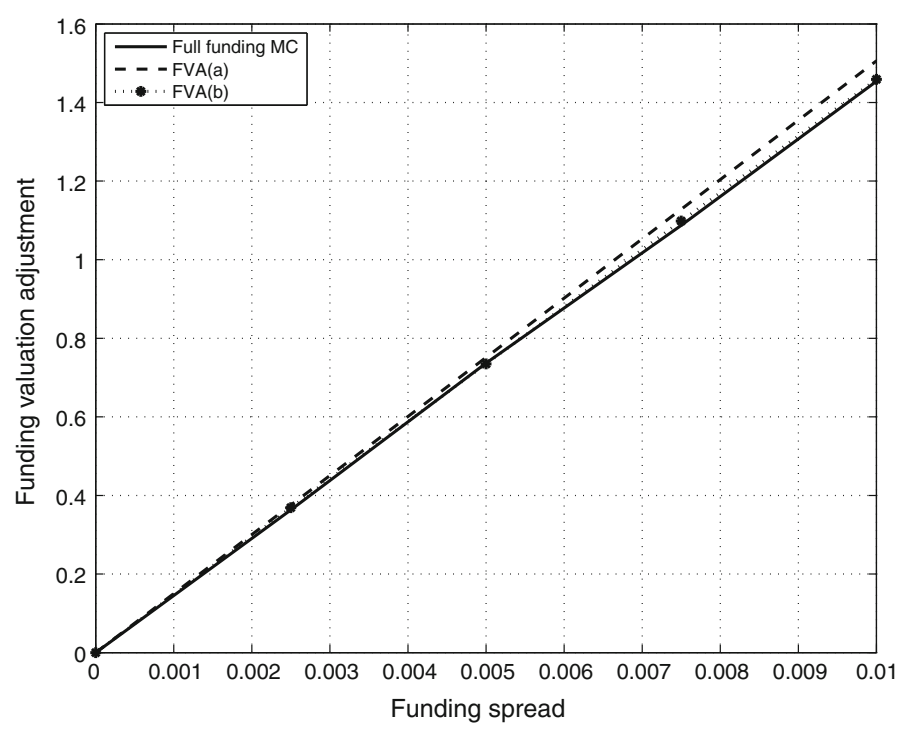

Fig. 1 Funding valuation adjustment of a long call position as a function of symmetric funding spreads $s_{f}:=\hat{f}-r$ with $\hat{f}:=f^{+}=f^{-}$. The adjustments are computed under the assumption of no default risk nor collateralization

\subsection{Complete Valuation Under Credit Risk, Collateral, and Asymmetric Funding}

Let us now switch on credit risk and consider the impact of asymmetric funding rates. Due the presence of collateral as a control variate, the accuracy is quite good in our example even for relatively small numbers of sample paths. Based on the simulation of 1,000 paths, Tables 1 and 2 report the results of a ceteris paribus analysis of funding risk under counterparty credit risk and collateralization. Specifically, we investigate how the value of a deal changes for different values of the borrowing (lending) rate $f^{+}\left(f^{-}\right)$while keeping the lending (borrowing) rate fixed to $100 \mathrm{bps}$. When both funding rates are equal to $100 \mathrm{bps}$, the deal is funded at the risk-free rate and we are in the classical derivatives valuation setting.

Remark 4 (Potential Arbitrage).

Note that if $f^{+}<f^{-}$arbitrage opportunities might be present, unless certain constraints are imposed on the funding policy of the treasury. Such constraints may look unrealistic and may be debated themselves from the point of view of arbitrageability, but since our point here is strictly to explore the impact of asymmetries in the funding equations, we will still apply our framework to a few examples where $f^{+}<f^{-}$.

Table 1 reports the impact of changing funding rates for a call position when the posted collateral may not be used for funding the deal, i.e. rehypothecation is not allowed. First, we note that increasing the lending rate for a long position has a much 
Table 1 Price impact of funding with default risk and collateralization

\begin{tabular}{|c|c|c|c|c|}
\hline \multirow[t]{2}{*}{ Funding ${ }^{\mathrm{a}}$ (bps) } & \multicolumn{2}{|c|}{ Default risk, low ${ }^{b}$} & \multicolumn{2}{|c|}{ Default risk, high ${ }^{\mathrm{c}}$} \\
\hline & Long & Short & Long & Short \\
\hline \multicolumn{5}{|c|}{ Borrowing rate $f^{+}$} \\
\hline 100 & $28.70(0.15)$ & $-28.72(0.15)$ & $29.06(0.21)$ & $-29.07(0.21)$ \\
\hline 125 & $28.53(0.17)$ & $-29.37(0.18)$ & $28.91(0.21)$ & $-29.70(0.20)$ \\
\hline 150 & $28.37(0.18)$ & $-30.02(0.22)$ & $28.75(0.22)$ & $-30.34(0.20)$ \\
\hline 175 & $28.21(0.20)$ & $-30.69(0.27)$ & $28.60(0.22)$ & $-30.99(0.21)$ \\
\hline 200 & $28.05(0.21)$ & $-31.37(0.31)$ & $28.45(0.22)$ & $-31.66(0.25)$ \\
\hline \multicolumn{5}{|l|}{ Lending rate $f^{-}$} \\
\hline 100 & $28.70(0.15)$ & $-28.72(0.15)$ & $29.06(0.21)$ & $-29.07(0.21)$ \\
\hline 125 & $29.35(0.18)$ & $-28.56(0.17)$ & $29.69(0.20)$ & $-28.92(0.21)$ \\
\hline 150 & $30.01(0.22)$ & $-28.40(0.18)$ & $30.34(0.20)$ & $-28.76(0.22)$ \\
\hline 175 & $30.68(0.27)$ & $-28.23(0.20)$ & $31.00(0.21)$ & $-28.61(0.22)$ \\
\hline 200 & $31.37(0.32)$ & $-28.07(0.39)$ & $31.67(0.25)$ & $-28.46(0.22)$ \\
\hline
\end{tabular}

Standard errors of the price estimates are given in parentheses

${ }^{a}$ Ceteris paribus changes in one funding rate while keeping the other fixed to $100 \mathrm{bps}$

${ }^{\mathrm{b}}$ Based on the joint default distribution $D_{\text {low }}$ with low dependence

${ }^{\mathrm{c}}$ Based on the joint default distribution $D_{\text {high }}$ with high dependence

Table 2 Price impact of funding with default risk, collateralization, and rehypothecation

\begin{tabular}{|c|c|c|c|c|}
\hline \multirow[t]{2}{*}{ Funding $^{\mathrm{a}}$ (bps) } & \multicolumn{2}{|c|}{ Default risk, low ${ }^{\mathrm{b}}$} & \multicolumn{2}{|c|}{ Default risk, high ${ }^{\mathrm{c}}$} \\
\hline & Long & Short & Long & Short \\
\hline \multicolumn{5}{|c|}{ Borrowing rate $f^{+}$} \\
\hline 100 & $28.70(0.15)$ & $-28.73(0.15)$ & $29.07(0.22)$ & $-29.08(0.22)$ \\
\hline 125 & $28.55(0.17)$ & $-29.56(0.19)$ & $28.92(0.22)$ & $-29.89(0.20)$ \\
\hline 150 & $28.39(0.18)$ & $-30.40(0.24)$ & $28.77(0.22)$ & $-30.72(0.20)$ \\
\hline 175 & $28.23(0.20)$ & $-31.26(0.30)$ & $28.63(0.22)$ & $-31.56(0.23)$ \\
\hline 200 & $28.07(0.22)$ & $-32.14(0.36)$ & $28.48(0.22)$ & $-32.43(0.29)$ \\
\hline \multicolumn{5}{|l|}{ Lending rate $f^{-}$} \\
\hline 100 & $28.70(0.15)$ & $-28.73(0.15)$ & $29.07(0.22)$ & $-29.08(0.22)$ \\
\hline 125 & $29.53(0.19)$ & $-28.57(0.17)$ & $29.07(0.22)$ & $-28.93(0.22)$ \\
\hline 150 & $30.38(0.24)$ & $-28.42(0.18)$ & $32.44(0.29)$ & $-28.78(0.22)$ \\
\hline 175 & $31.25(0.30)$ & $-28.26(0.20)$ & $36.19(0.61)$ & $-28.64(0.22)$ \\
\hline 200 & $32.14(0.37)$ & $-28.10(0.22)$ & $32.44(0.29)$ & $-28.49(0.22)$ \\
\hline
\end{tabular}

Standard errors of the price estimates are given in parentheses

${ }^{a}$ Ceteris paribus changes in one funding rate while keeping the other fixed to $100 \mathrm{bps}$

${ }^{\mathrm{b}}$ Based on the joint default distribution $D_{\text {low }}$ with low dependence

${ }^{\mathrm{c}}$ Based on the joint default distribution $D_{\text {high }}$ with high dependence 
larger impact than increasing the borrowing rate. This is due to the fact that a call option is just a one-sided contract. Recall that $F$ is defined as the cash account needed as part of the derivative replication strategy or, analogously, the cash account required to fund the hedged derivative position. To hedge a long call, the investor goes short in a delta position of the underlying asset and invests excess cash in the treasury at $f^{-}$. Correspondingly, to hedge the short position, the investor enters a long delta position in the stock and finances it by borrowing cash from the treasury at $f^{+}$, so changing the lending rate only has a small effect on the deal value. Finally, due to the presence of collateral, we observe an almost similar price impact of funding under the two different default distributions $D_{\text {low }}$ and $D_{\text {high }}$.

Finally, assuming cash collateral, we consider the case of rehypothecation and allow the investor and counterparty to use any posted collateral as a funding source. If the collateral is posted to the investor, this means it effectively reduces his costs of funding the delta-hedging strategy. As the payoff of the call is one-sided, the investor only receives collateral when he holds a long position in the call option. But as he hedges this position by short-selling the underlying stock and lending the excess cash proceeds, the collateral adds to his cash lending position and increases the funding benefit of the deal. Analogously, if the investor has a short position, he posts collateral to the counterparty and a higher borrowing rate would increase his costs of funding the collateral he has to post as well as his delta-hedge position. Table 2 reports the results for the short and long positions in the call option when rehypothecation is allowed. Figures 2 and 3 plot the values of collateralized long and short positions in the call option as a function of asymmetric funding spreads. In addition, Fig. 4

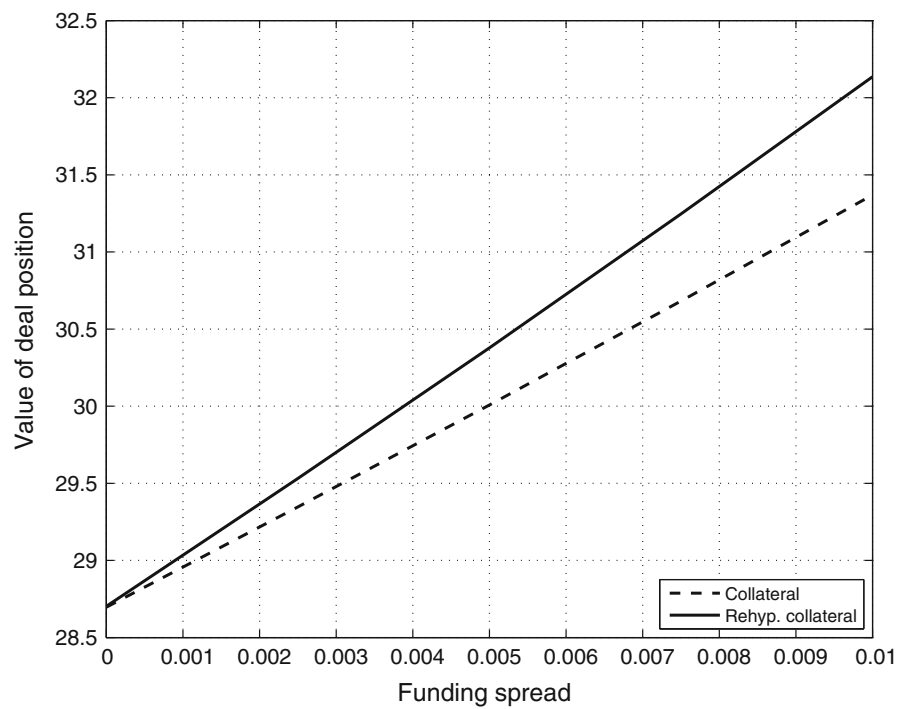

Fig. 2 The value of a long call position for asymmetric funding spreads $s_{f}^{-}=f^{-}-r$, i.e. fixing $f^{+}=r=0.01$ and varying $f^{-} \in(0.01,0.0125,0.015,0.0175,0.02)$ 


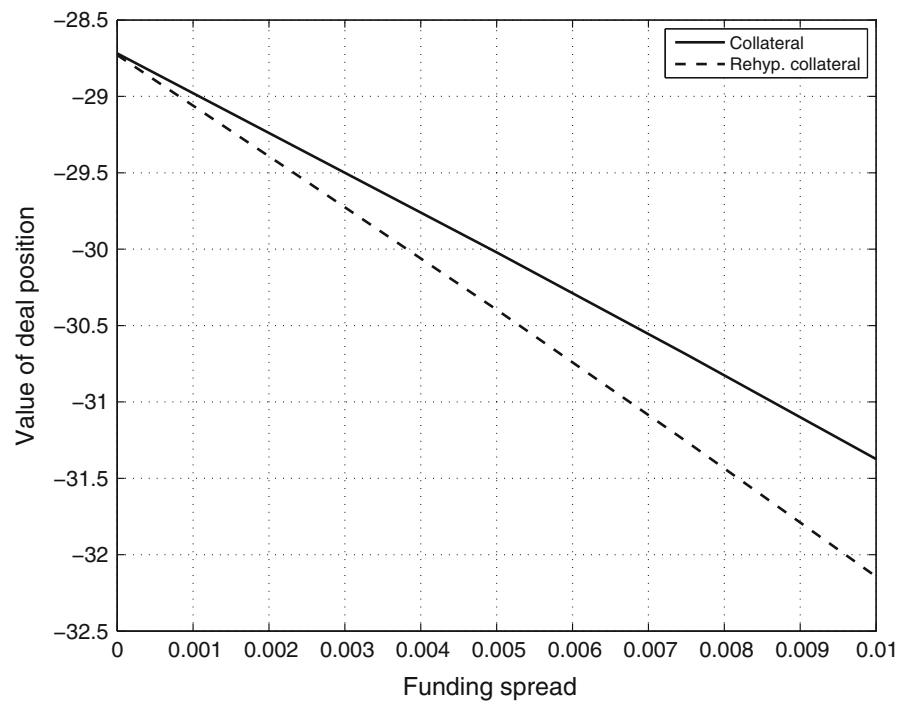

Fig. 3 The value of a short call position for asymmetric funding spreads $s_{f}^{+}=f^{+}-r$, i.e. fixing $f^{-}=r=0.01$ and varying $f^{+} \in(0.01,0.0125,0.015,0.0175,0.02)$

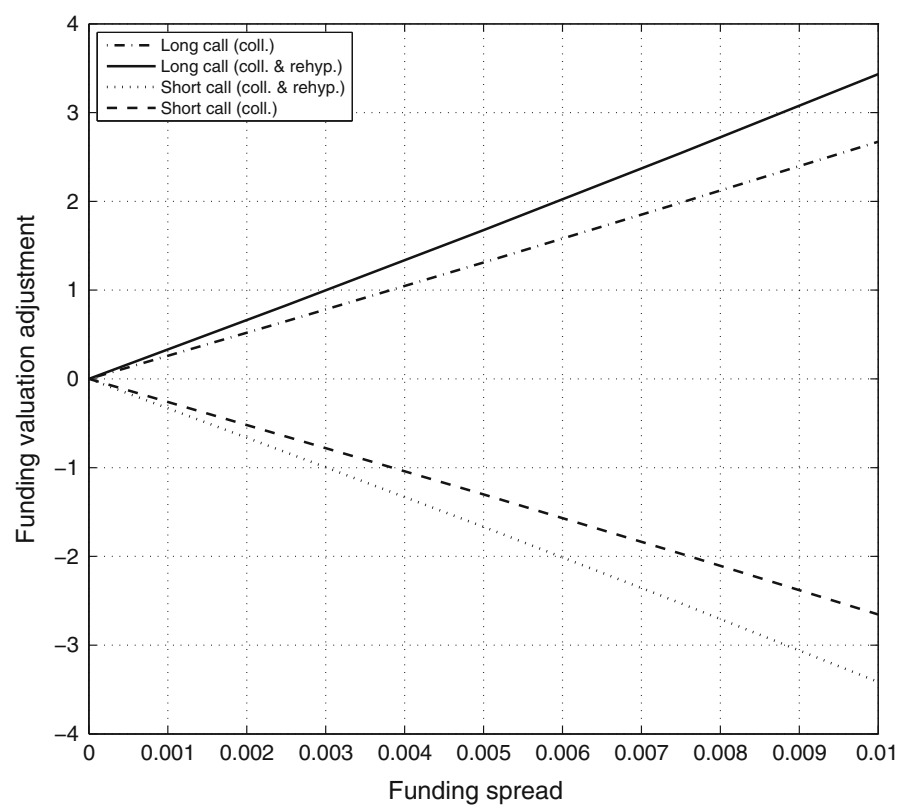

Fig. 4 Funding valuation adjustment as a function of asymmetric funding spreads. The adjustments are computed under the presence of default risk and collateralization 
reports the FVA with respect to the magnitude of the funding spreads, where the FVA is defined as the difference between the full funding-inclusive deal price and the full deal price, but symmetric funding rates equal to the risk-free rate. Recall that the collateral rates are equal to the risk-free rate, so the LVA collapses to zero in these examples.

This shows that funding asymmetry matters even under full collateralization when there is no repo market for the underlying stock. In practice, however, the dealer cannot hedge a long call by shorting a stock he does not own. Instead, he would first borrow the stock in a repo transaction and then sell it in the spot market. Similarly, to enter the long delta position needed to hedge a short call, the dealer could finance the purchase by lending the stock in a reverse repo transaction. Effectively, the delta position in the underlying stock would be funded at the prevailing repo rate. Thus, once the delta hedge has to be executed through the repo market, there is no funding valuation adjustment (meaning any dependence on the funding rate $\tilde{f}$ drops out) given the deal is fully collateralized, but the underlying asset still grows at the repo rate. If there is no credit risk, this would leave us with the result of Piterbarg [36]. However, if the deal is not fully collateralized or the collateral cannot be rehypothecated, funding costs enter the picture even when there is a repo market for the underlying stock.

\subsection{Nonlinearity Valuation Adjustment}

In this last section we introduce a nonlinearity valuation adjustment, and to stay within the usual jargon of the business, we abbreviate it NVA. The NVA is defined by the difference between the true price $\bar{V}$ and a version of $\bar{V}$ where nonlinearities have been approximated away through blunt symmetrization of rates and possibly a change in the close-out convention from replacement close-out to risk-free closeout. This entails a degree of double counting (both positive and negative interest). In some situations the positive and negative double counting will offset each other, but in other cases this may not happen. Moreover, as pointed out by Brigo et al. [10], a further source of double counting might be neglecting the first-to-default time in bilateral CVA/DVA valuation. This is done in a number of industry approximations.

Let $\hat{V}$ be the resulting price when we replace both $f^{+}$and $f^{-}$by $\hat{f}:=\left(f^{+}+\right.$ $\left.f^{-}\right) / 2$ and adopt a risk-free close-out at default in our valuation framework. A further simplification in $\hat{V}$ could be to neglect the first-to-default check in the close-out. We have the following definition

Definition 1 (Nonlinearity Valuation Adjustment, NVA)

NVA is defined as

$$
\mathrm{NVA}_{t} \triangleq \bar{V}_{t}-\hat{V}_{t}
$$

where $\bar{V}$ denotes the full nonlinear deal value while $\hat{V}$ denotes an approximate linearized price of the deal. 


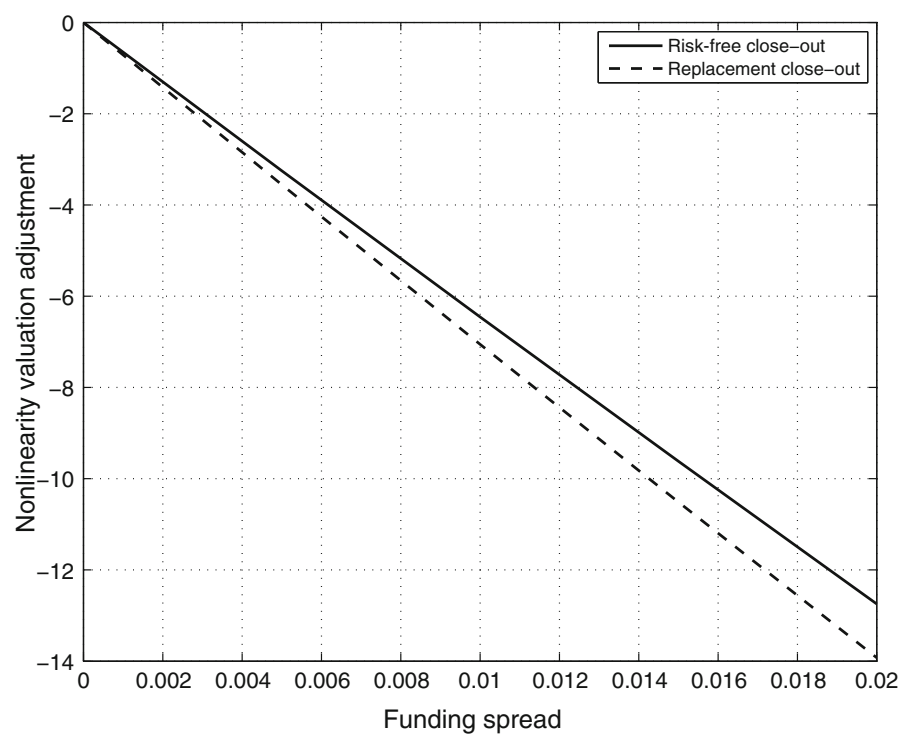

Fig. 5 Nonlinearity valuation adjustment (in percentage of $\hat{V}$ ) for different funding spreads $s_{f}^{+}=$ $f^{+}-f^{-} \in(0,0.005,0.01,0.015,0.02)$ and fixed $\hat{f}=\left(f^{+}+f^{-}\right) / 2=0.01$

As an illustration, we revisit the above example of an equity call option and analyze the NVA in a number of cases. The results are reported in Figs. 5 and 6.

In both figures, we compare NVA under risk-free close-out and under replacement close-out. We can see that, depending on the direction of the symmetrization, NVA may be either positive or negative. As the funding spread increases, NVA grows in absolute value. In addition, adopting the replacement close-out amplifies the presence of double counting. The NVA accounts for up to $15 \%$ of the full deal price $\bar{V}$ depending on the funding spread-a relevant figure in a valuation context.

Table 3 reports (a) \% $\mathrm{NVA}$ denoting the fraction of the approximated deal price $\hat{V}$ explained by NVA, and (b) \%NVA denoting the fraction of the full deal price $\bar{V}$ (with symmetric funding rates equal to the risk-free rate $r$ ) explained by NVA. Notice that for those cases where we adopt a risk-free close-out at default, the results primarily highlight the double-counting error due to symmetrization of borrowing and lending rates. We should point out that close-out nonlinearities play a limited role here, due to absence of wrong way risk. An analysis of close-out nonlinearity under wrong way risk is under development.

Finally, it should be noted that linearization may in fact be done in arbitrarily many ways by playing with the discount factor, hence taking the average of two funding rates as in our definition of NVA is not necessarily the best one. However, we postpone further investigations into this interesting topic for future research. 


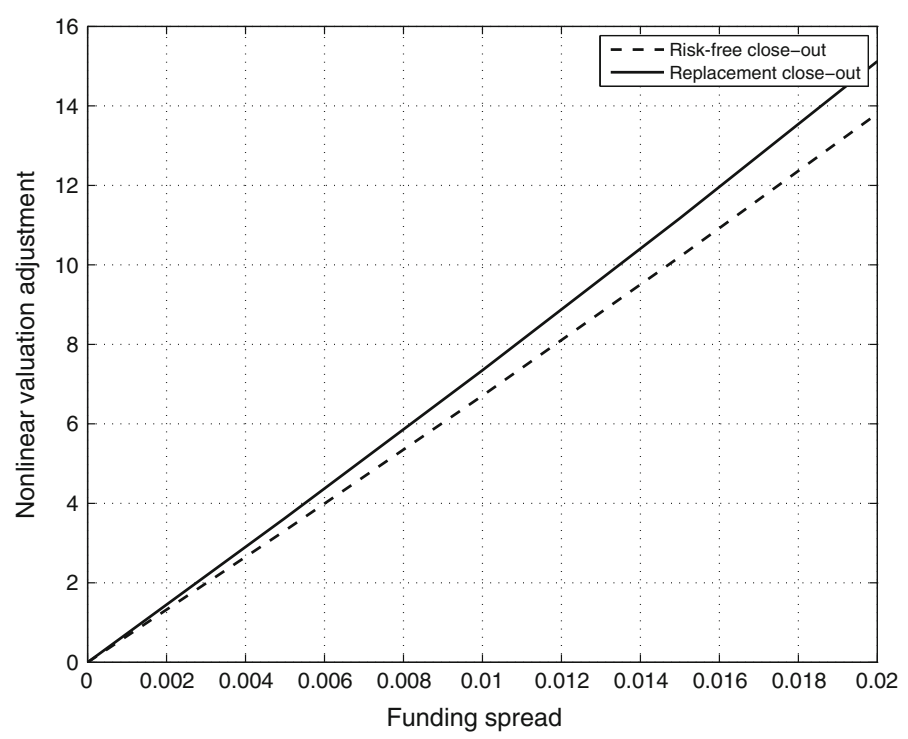

Fig. 6 Nonlinearity valuation adjustment (in percentage of $\hat{V}$ ) for different funding spreads $s_{f}^{-}=$ $f^{-}-f^{+} \in(0,0.005,0.01,0.015,0.02)$ and fixed $\hat{f}=\left(f^{+}+f^{-}\right) / 2=0.01$

Table $3 \%$ NVA with default risk, collateralization and rehypothecation

\begin{tabular}{l|l|l|l|l|l}
\hline \multirow{2}{*}{ Funding rates } & \multicolumn{3}{l}{ Risk free } & Replacement \\
\cline { 3 - 6 } \multicolumn{2}{l|}{} & $\% \widehat{\mathrm{NVA}}$ & $\% \mathrm{NVA}$ & $\% \widehat{\mathrm{NVA}}$ & $\% \mathrm{NVA}$ \\
\hline$s_{f}^{\mathrm{b}}(\mathrm{bps})$ & $\hat{f}(\mathrm{bps})$ & \multicolumn{5}{l}{} \\
\hline 0 & 100 & $0 \%$ & $0 \%$ & $0 \%$ & $0 \%$ \\
\hline 25 & 112.5 & $1.65 \%$ & $1.67 \%$ & $1.79 \%$ & $1.81 \%$ \\
\hline 50 & 125 & $3.31 \%$ & $3.39 \%$ & $3.58 \%$ & $3.68 \%$ \\
\hline 75 & 137.5 & $5.02 \%$ & $5.19 \%$ & $5.39 \%$ & $5.61 \%$ \\
\hline 100 & 150 & $6.70 \%$ & $7.01 \%$ & $7.24 \%$ & $7.62 \%$ \\
\hline
\end{tabular}

${ }^{\mathrm{a}}$ Funding spread $s_{f}=f^{-}-f^{+}$

${ }^{\mathrm{b}}$ The prices of the call option are based on the joint default distribution $D_{\text {high }}$ with high dependence

\section{Conclusions and Financial Implications}

We have developed a consistent framework for valuation of derivative trades under collateralization, counterparty credit risk, and funding costs. Based on no arbitrage, we derived a generalized pricing equation where CVA, DVA, LVA, and FVA are introduced by simply modifying the payout cash flows of the trade. The framework is flexible enough to accommodate actual trading complexities such as asymmetric collateral and funding rates, replacement close-out, and rehypothecation of posted collateral. Moreover, we presented an invariance theorem showing that the valuation 
framework does not depend on any theoretical risk-free rate, but is purely based on observable market rates.

The generalized valuation equation under credit, collateral, and funding takes the form of a forward-backward SDE or semi-linear PDE. Nevertheless, it can be recast as a set of iterative equations which can be efficiently solved by a proposed leastsquares Monte Carlo algorithm. Our numerical results confirm that funding risk as well as asymmetries in borrowing and lending rates have a significant impact on the ultimate value of a derivatives transaction.

Introducing funding costs into the pricing equation makes the valuation problem recursive and nonlinear. The price of the deal depends on the trader's funding strategy, while to determine the funding strategy we need to know the deal price itself. Credit and funding risks are in general non-separable; this means that FVA is not an additive adjustment, let alone a discounting spread. Thus, despite being common practice among market participants, treating it as such comes at the cost of double counting. We introduce the "nonlinearity valuation adjustment" (NVA) to quantify the effect of double counting and we show that its magnitude can be significant under asymmetric funding rates and replacement close-out at default.

Furthermore, valuation under funding costs is no longer bilateral as the particular funding policy chosen by the dealer is not known to the client, and vice versa. As a result, the value of the trade will generally be different to the two counterparties.

Finally, valuation depends on the level of aggregation; asset portfolios cannot simply be priced separately and added up. Theoretically, valuation is conducted under deal or portfolio-dependent risk-neutral measures. This has clear operational consequences for financial institutions; it is difficult for banks to establish CVA and FVA desks with separate, clear-cut responsibilities. In theory, they should adopt a consistent valuation approach across all trading desks and asset classes. A trade should be priced on an appropriate aggregation-level to quantify the value it actually adds to the business. This, of course, prompts to the old distinction between price and value: Should funding costs be charged to the client or just included internally to determine the profitability of a particular trade? The relevance of this question is reinforced by the fact that the client has no direct control on the funding policy of the bank and therefore cannot influence any potential inefficiencies for which he or she would have to pay.

While holistic trading applications may be unrealistic with current technology, our valuation framework offers a unique understanding of the nature and presence of nonlinearities and paves the way for developing more suitable and practical linearizations. The latter topic we will leave for future research.

Acknowledgements The KPMG Center of Excellence in Risk Management is acknowledged for organizing the conference "Challenges in Derivatives Markets - Fixed Income Modeling, Valuation Adjustments, Risk Management, and Regulation".

Open Access This chapter is distributed under the terms of the Creative Commons Attribution 4.0 International License (http://creativecommons.org/licenses/by/4.0/), which permits use, duplication, adaptation, distribution and reproduction in any medium or format, as long as you give 
appropriate credit to the original author(s) and the source, a link is provided to the Creative Commons license and any changes made are indicated.

The images or other third party material in this chapter are included in the work's Creative Commons license, unless indicated otherwise in the credit line; if such material is not included in the work's Creative Commons license and the respective action is not permitted by statutory regulation, users will need to obtain permission from the license holder to duplicate, adapt or reproduce the material.

\section{References}

1. Bielecki, T., Rutkowski, M.: Credit Risk: Modeling, Valuation and Hedging. Springer, Berlin (2002)

2. Brigo, D., Capponi, A.: Bilateral counterparty risk with application to CDSs. Working Paper, pp. 241-268 (2008)

3. Brigo, D., Chourdakis, K.: Counterparty risk for credit default swaps: impact of spread volatility and default correlation. Int. J. Theor. Appl. Financ. 12(07), 1007-1026 (2009)

4. Brigo, D., Masetti, M.: Risk neutral pricing of counterparty risk. In: Pykhtin, M. (ed.) Counterparty Credit Risk Modeling: Risk Management, Pricing and Regulation, Risk Books (2005)

5. Brigo, D., Pallavicini, A.: Counterparty risk under correlation between default and interest rates. In: Miller, J., Edelman, D., Appleby, J. (eds.) Numerical Methods for Finance, Chapman Hall (2007)

6. Brigo, D., Pallavicini, A.: Nonlinear consistent valuation of CCP cleared or CSA bilateral trades with initial margins under credit, funding and wrong-way risks. J. Financ. Eng. 1(1), 1-60 (2014)

7. Brigo, D., Capponi, A., Pallavicini, A., Papatheodorou, V.: Collateral margining in arbitragefree counterparty valuation adjustment including re-hypotecation and netting. Working Paper (2011)

8. Brigo, D., Morini, M., Tarenghi, M.: Equity return swap valuation under counterparty risk. In: Bielecki, T., Brigo, D., Patras, F. (eds.) Credit Risk Frontiers: Sub-prime Crisis, Pricing and Hedging, CVA, MBS, Ratings and Liquidity, pp. 457-484. Wiley (2011)

9. Brigo, D., Pallavicini, A., Papatheodorou, V.: Arbitrage-free valuation of bilateral counterparty risk for interest-rate products: impact of volatilities and correlations. Int. J. Theor. Appl. Financ. 14(6), 773-802 (2011)

10. Brigo, D., Buescu, C., Morini, M.: Counterparty risk pricing: impact of closeout and first-todefault times. Int. J. Theor. Appl. Financ. 15, 1250039-1250039 (2012)

11. Brigo, D., Morini, M., Pallavicini, A.: Counterparty Credit Risk. Collateral and Funding with Pricing Cases for All Asset Classes. Wiley, Chichester (2013)

12. Brigo, D., Capponi, A., Pallavicini, A.: Arbitrage-free bilateral counterparty risk valuation under collateralization and re-hypothecation with application to CDS. Math. Financ. 24(1), 125-146 (2014)

13. Brigo, D., Liu, Q., Pallavicini, A., Sloth, D.: Nonlinear Valuation Under Margining and Funding Costs With Residual Credit Risk: A Unified Approach. Handbook in Fixed-Income Securities. Wiley, New Jersey (2014)

14. Brigo, D., Liu, Q., Pallavicini, A., Sloth, D.: Nonlinear valuation under collateral, credit risk and funding costs: a numerical case study extending Black-Scholes. arXiv preprint arXiv:1404.7314 (2014)

15. Brigo, D., Francischello, M., Pallavicini, A.: Invariance, existence and uniqueness of solutions of nonlinear valuation PDEs and FBSDEs inclusive of credit risk, collateral and funding costs. arXiv preprint arXiv:1506.00686. A refined version of this paper appears in the present volume (2015) 
16. Burgard, C., Kjaer, M.: Partial differential equation representations of derivatives with counterparty risk and funding costs. J. Credit Risk 7(3), 1-19. www.ssrn.com/abstract=1605307 (2011)

17. Burgard, C., Kjaer, M.: In the balance. Risk Mag. (2011)

18. Carriere, J.F.: Valuation of the early-exercise price for options using simulations and nonparametric regression. Insur. Math. Econ. 19(1), 19-30 (1996)

19. Castagna, A.: Funding, liquidity, credit and counterparty risk: links and implications. Working Paper. www.ssrn.com (2011)

20. Cherubini, U.: Counterparty risk in derivatives and collateral policies: the replicating portfolio approach. In: Tilman, L. (ed.) ALM of Financial Institutions. Institutional Investor Books (2005)

21. Crépey, S.: A BSDE approach to counterparty risk under funding constraints. Working Paper. www.grozny.maths.univ-evry.fr/pages_perso/crepey (2011)

22. Crépey, S.: Bilateral counterparty risk under funding constraints Part I: Pricing. Math. Financ. 25(1), 1-22 (2012a)

23. Crépey, S.: Bilateral counterparty risk under funding constraints Part II: CVA. Math. Financ. 25(1), 23-50 (2012b)

24. Crépey, S., Bielecki, T., Brigo, D.: Counterparty Risk and Funding: A Tale of Two Puzzles. Taylor \& Francis, Abingdon (2014)

25. Fries, C.: Discounting revisited: valuation under funding, counterparty risk and collateralization. Working Paper. www.ssrn.com (2010)

26. Green, A.D., Kenyon, C., Dennis, C.R.: KVA: capital valuation adjustment. Risk (2014)

27. Gregory, J.K.: Being two faced over counterparty credit risk. Risk Mag. 22, 86-90 (2009)

28. Hull, J., White, A.: The FVA debate. Risk Mag. 8, (2012)

29. ISDA. ISDA close-out amount protocol. Working Paper (2009). www.isda.com

30. Longstaff, F.A., Schwartz, E.S.: Valuing American options by simulation: a simple least-squares approach. Rev. Financ. Stud. 14(1), 113-147 (2001)

31. Morini, M., Prampolini, A.: Risky funding: a unified framework for counterparty and liquidity charges. Risk Mag. (2011)

32. Pallavicini, A., Brigo, D.: Interest-rate modelling in collateralized markets: multiple curves, credit-liquidity effects, CCPs. arXiv:1212.2383, ssrn.com (2013)

33. Pallavicini, A., Perini, D., Brigo, D.: Funding Valuation Adjustment: FVA consistent with CVA, DVA, WWR. Netting and re-hyphotecation. arXiv.org, ssrn.com, Collateral (2011)

34. Pallavicini, A., Perini, D., Brigo, D.: Funding, collateral and hedging: uncovering the mechanics and the subtleties of funding valuation adjustments. arXiv preprint arXiv:1210.3811 (2012)

35. Parker, E., McGarry, A.: The isda master agreement and csa: close-out weaknesses exposed in the banking crisis and suggestions for change. Butterworths J. Int. Bank. Law 1 (2009)

36. Piterbarg, V.: Funding beyond discounting: collateral agreements and derivatives pricing. Risk Mag. 2, 97-102 (2010)

37. Sloth, D.: A Journey into the Dark Arts of Quantitative Finance. Aarhus University, Department of Economics and Business (2013)

38. Tilley, J.A.: Valuing American options in a path simulation model. Trans. Soc. Actuar. 45(83), 104 (1993)

39. Tsitsiklis, J.N., Van Roy, B.: Regression methods for pricing complex American-style options. IEEE Trans. Neural Netw. 12(4), 694-703 (2001)

40. Weeber, P., Robson, E.S.: Market practices for settling derivatives in bankruptcy. ABI J. 3435(9), 76-78 (2009) 